\title{
Effects of high shear on the structure and thickness of turbulent premixed methane/air flames stabilized on a bluff-body burner
}

\author{
Gaetano Magnotti Robert S. Barlow \\ Combustion Research Facility, Sandia National Laboratories, Livermore, CA 94550 USA
}

\begin{abstract}
The effects of preferential transport and strain on the scalar structure (profiles of major species, elemental ratios) of turbulent premixed bluff-body stabilized flames are examined using line-imaged Raman/Rayleigh/CO-LIF diagnostics combined with crossed-planar Rayleigh imaging to determine the 3D flame orientation. Comparison of the experimental measurements with laminar flame calculations shows strong effects of preferential diffusion on the flame structure and the product state in lean and rich flames. Measurements of the flame orientation show a strong correlation between the flame-front normal angle and the strength of the preferential transport effects. As the flame-front angle decreases (by increasing the reactant velocity or decreasing the distance from the surface), the coupling between the preferential diffusion through the flame brush and the recirculation region is increased, enhancing the preferential transport effects. Spatial profiles and flame thickness measurements are discussed to evaluate how the strain and the turbulence affect the flame. In fuel-lean flames, as the velocity increases, eddies smaller than the flame thickness, but larger than the reaction layer, penetrate the preheat zone, improving the mixing and thickening the flame. Higher velocities are associated with higher levels of strain, which mitigate the thickening effect of the turbulence. Increases of the flame thickness up to $10 \%$ were observed. In fuel-rich flames, both the strain and the turbulence contribute to the thickening of the flame, and a flame thickness up to 2.5 times larger than the unstrained laminar thickness is observed. Changes are not limited to the preheat zone, but affect the entire flame structure. Progress variable scalar dissipation rate profiles are also discussed.
\end{abstract}

Keywords: Turbulent premixed flames; Bluff-body flames; Differential diffusion; Preferential transport; Multiscalar diagnostics.

\section{Introduction}

In practical premixed combustors the turbulent flame brush is often stabilized in a region of high shear by contact with recirculating combustion products, so there is motivation to better understand the effects of high shear on the flame structure. Bluff-body burners reproduce some of the effects of high shear and product recirculation encountered in such combustors, but the simpler geometry makes acquisition and interpretation of experimental results easier [1]. Most et al. [2] investigated flame lift-off mechanism in premixed $\mathrm{CH}_{4}$-air flames stabilized over a bluff-body, using $\mathrm{OH}$ planar laser-induced fluorescence (OH-PLIF). Hartung et al. [3] applied stereoscopic PIV and OH PLIF to study the effect of heat release on turbulence and scalar-turbulence interaction in a premixed ethylene-air flame stabilized over a bluff-body. Nandula et al. [4] performed single-point Raman/Rayleigh measurements of temperature and major species concentrations in an enclosed, bluff-body stabilized, lean premixed $\mathrm{CH}_{4}$-air flame. Extensive experimental studies, including laser Doppler velocimetry [5], 2D Rayleigh scattering, single-point [6] and 1D Raman/Rayleigh measurements [7], have been performed on the TECFLAM flame, a swirling natural gas/air premixed flame, stabilized over a bluff-body. Similarly, extensive experimental studies have been 
conducted on stratified and homogeneous flames stabilized on a bluff-body burner developed by Cambridge and Sandia [8-10]. Piloted Bunsen flames, such those investigated by Chen et al. [11] using line imaged Rayleigh/Raman/OH LIF, are also relevant to the topic of this paper, because of the high shear near the base of the flame.

Although several of the studies mentioned above involved Raman/Rayleigh measurements, spatial resolution and measurement precision sufficient to investigate the instantaneous internal scalar structure of premixed flames has been achieved only recently [12]. Using this improved 1D Raman/Rayleigh/CO-LIF instrument coupled with cross planar $\mathrm{OH}$ imaging, Sweeney et al. [9, 13] obtained measurements of temperature, major species concentration, flame orientation, and scalar dissipation on the Cambridge/Sandia stratified swirl burner. Barlow et al. [8] compared species concentrations and atom ratios from the Cambridge/Sandia burner and from a simple premixed bluff-body burner to unstrained laminar calculations, and they observed that $\mathrm{C} / \mathrm{H}$ and $\mathrm{C} / \mathrm{O}$ atom ratios were not conserved going from reactants to products across the flame brush. This was attributed to preferential diffusion of $\mathrm{H}_{2}$ and $\mathrm{H}_{2} \mathrm{O}$ through the preheat zone, ahead of $\mathrm{CO}_{2}$ and $\mathrm{CO}$, followed by convective transport downstream and away from the flame brush. Furthermore, the preferential transport effects were shown to be enhanced when the flame brush was located in the high shear region adjacent to the bluff-body recirculation zone. As noted in [8], measurements in a pilot-stabilized annular flame did not show measurable changes in the flame structure or product composition due to preferential diffusion effects, reinforcing the interpretation of the key role played by the recirculation zone. Additional experiments [14] covering a wider range of flow parameters showed that the atom imbalances reached a limiting state as velocity continued to increase, suggesting that preferential transport effects may extend to the high Reynolds number encountered in practical applications, and motivates further studies. Numerical simulations by Katta et al. [15] of a fuel-lean methane flame on a similar bluff-body burner confirmed that atom balances are altered in this configuration and showed that preferential transport effects are strongest at axial locations close to the corner of the bluff-body.

The effects of preferential species diffusion on the flame structure and the propagation rate of turbulent premixed flames have been the subject of many numerical and experimental studies. A comprehensive review by Lipatnikov and Chomiak [16], summarizes findings from several numerical and experimental studies, showing that preferential transport effects can remain important in moderately and highly turbulent flames. Formation of super-adiabatic pockets has been observed in lean hydrogen-air flames [17-19] and rich hydrocarbon flames [20, 21], as a consequence of preferential diffusion. DNS studies $[22,23]$ showed that focusing and defocusing of fast diffusing species strongly affects the flame structure. Studies in premixed $\mathrm{H}_{2}$-air flames reveal the importance of the Lewis number, defined as the ratio of the thermal to the fuel mass diffusivity, in determining the topology and the propagation speed of premixed flames [16-19]. Several models that account for the effects of Lewis number in turbulent premixed flames have been developed [16, 24], and recent LES studies have successfully modeled the effects of preferential transport of profiles of equivalence ratio in the Cambridge/Sandia flames [25, 26].

The present study examines in more detail the effects of preferential transport and high shear on the scalar structure of bluff-body stabilized flames. A simple annular bluff-body burner similar to that of $[8,14]$ is used, and the Raman/Rayleigh/CO-LIF multi-scalar diagnostic system used in the previous experiments is combined with Cross-Planar Rayleigh Imaging (CPRI) for instantaneous measurements of the flame-front orientation. This allows quantitative determination of flame thickness and the 3D gradient in progress variable. We present results from fuel-lean $(\Phi=0.75)$ and fuel-rich $(\Phi=1.23)$ flames, each at three bulk reactant velocities. Measurements are obtained across 
full radial profiles at six axial locations, ranging from $5 \mathrm{~mm}$ to $20 \mathrm{~mm}$ from the surface, whereas previous measurements focused just on the flame zone at a distance of $10 \mathrm{~mm}$ from the surface. With this more complete mapping of the recirculation region and with the addition of flame orientation measurements, several questions raised by the previous studies are addressed.

First, numerical simulations by Katta et al. [15], performed on a similar bluff-body burner but for laminar flow, showed significant spatial variation in the effects of preferential transport on atom imbalances, with the largest effects seen near the corner of the bluff body. Here we show full radial profiles of temperature and major species mass fractions as function of the reactant velocity, the distance from the burner, and the equivalence ratio. In particular, the varying effects of the preferential transport on the gas composition in the recirculation region are discussed.

Second, it was reported in [14] that, at the highest velocity considered, the $\mathrm{CO}_{2}$ and $\mathrm{O}_{2}$ mass fraction profiles in temperature space have a near-linear trend, typical of highly strained flames. Profiles from laminar flame calculations at various strain rates were presented to show a qualitative similarity in the scalar structure to the experimental flame. The product state of the numerical simulation was set to the adiabatic temperature and composition, so a direct comparison with the measurements was not meaningful. In the present work we discuss the role of strain on the flame structure by comparing the measured profiles to opposed flow calculations with the product state matching the measured composition.

Third, Dunn et al. [14] plotted radial profiles of temperature, $\mathrm{CH}_{4}$ mass fraction, and $\mathrm{C} / \mathrm{H}$ atom ratio measured in the fuel-rich bluff-body stabilized premixed $\mathrm{CH}_{4}$ air flame at high reactant velocity, and they observed a thickening of the flame compared to spatial profiles from laminar strained and unstrained calculations. However, this comparison was only qualitative because the flame orientation was not measured, and spatial profiles could not be projected onto the flamenormal coordinate. The spatial structure of the flame is useful to assess the effects strain and the level of interaction between turbulence and flame properties, which is critical information for modeling turbulent premixed flames. In the premixed flame literature, different burning regimes have been identified [27], distinguished by the shape of the flame-front and by the spatial structure of the flame. Diagrams proposed to identify the burning regime based on the turbulence and flame properties are often inadequate to predict the flame structure, and experimental measurements are preferred. For example, in the thin reaction regime introduced by Peters [28], eddies smaller than the flame thickness, but larger than the reaction layer, penetrate into the preheat zone and transport the hot fluid away, enlarging the preheat zone but leaving the thickness of the reaction layer unaltered. Both thickening [29-31] and thinning [32,33] have been observed in turbulent premixed flames belonging to the thin reaction regimes of Peters' diagram [34]. In this work we map instantaneous spatial profiles onto the flame-normal coordinate before comparing the measured spatial structures of the flame-front to laminar strained and unstrained calculations in order to determine the importance of turbulence and strain as function of equivalence ratio, reactant velocity, and distance from the bluff-body surface.

Finally, measurements of the 3D scalar dissipation of the progress of reaction variable $c$ are presented. The scalar dissipation rate is representative of the rate at which scalar fluctuations are destroyed. It appears in most models of turbulent premixed and non-premixed combustion [35, 36] and is useful for development and validation of numerical models. Measurements of scalar dissipation rate in premixed flames are relatively scarce because of the high spatial resolution required to resolve structures within the flame front $[13,32,37,38]$. 


\section{Experimental Methods}

The bluff-body premixed burner (Fig. 1) used for this study is an improved version of the one used in the previous studies discussed above [8, 14]. It consists of a $12.7 \mathrm{~mm}$ center-body surrounded by a premixed flow passing through a $6.3 \mathrm{~mm}$ annular gap. A perforated plate placed in the annular gap, $35 \mathrm{~mm}$ upstream of the exit, acts as turbulence generator. Similar to the Cambridge/Sandia swirl burner [13], the improved version of the simple bluff-body burner features a ceramic bluff-body cap that replaces the stainless steel center-body of $[8,14]$. Another improvement with respect to the previous version of the burner is the addition of a $\mathrm{N}_{2}$ co-flow to isolate the premixed flow from room air. Experimental data have been collected at two equivalence ratios ( $\Phi=0.75$ and 1.23), and with three values of reactant bulk velocities. Error! Reference source not found. shows for the six test cases, the equivalence ratio, Reynolds number based on hydraulic diameter $R_{D h}$, bulk velocity $U_{b}$, and the ratio of bulk velocity to laminar flame speed $U_{b} / S_{L}\left(S_{L}\right.$ as reported in [39]). Flow rates were controlled through mass flow controllers calibrated against laminar flow elements, with $1 \%$ accuracy. The burner was mounted on a three axis translation stage, and experimental data were collected along radial profiles (coincident with the laser probe) at 6 axial locations 5.0, 7.5, 10, 12.5, 15 and $20 \mathrm{~mm}$ from the bluff-body surface. CPRI measurements below $10 \mathrm{~mm}$ were not possible because of excessive scattering from the bluff-body surface.

An updated version of the multi-scalar measurements diagnostic system described in [8] was used for the measurements here described. The system combined Rayleigh and Raman scattering and two photons CO-LIF for single-shot acquisition of temperature and major species concentration $\left(\mathrm{N}_{2}, \mathrm{O}_{2}\right.$, $\mathrm{CO}, \mathrm{CO}_{2}, \mathrm{CH}_{4}, \mathrm{H}_{2}, \mathrm{H}_{2} \mathrm{O}$ ) along a $6 \mathrm{~mm}$ probe line. The Raman-Rayleigh probe was provided by four frequency doubled $\mathrm{Nd}$ :YAG lasers, opportunely delayed in time, overlapped and sent through three optical delay lines, to generate a $1.4 \mathrm{~J} /$ pulse laser beam, temporally stretched over $400 \mathrm{~ns}$ to prevent optical breakdown. An UV laser beam at $230.1 \mathrm{~nm}$, overlapped to the $\mathrm{Nd}$ :YAG laser beams, was used for the CO-LIF (two-photon) process.

A pair of $150 \mathrm{~mm}$ achromatic lenses (Linos Photonics $\mathrm{f} / 2$ and $\mathrm{f} / 4$ ) focused the Raman/Rayleigh/CO-LIF signal onto the detection system. The main internal components included two custom-built motor-driven chopper wheels, six commercial camera lenses, a custom transmission grating (1200 lines/mm Kaiser Optical) and mirrors and filters to separate the signal from Raman scattering ( 550-700 nm), Rayleigh scattering $(532 \mathrm{~nm})$, and CO fluorescence ( 480$488 \mathrm{~nm}$ ). A non-intensified, low-noise, cryogenically-cooled CCD camera (Princeton Instruments VersArray 1300B with CryoTiger cooling unit, -110 C operating temperature) was used for Raman detection.

A Princeton Instruments 1340/400 EMB CCD camera was used for the Rayleigh signal, and an intensified CCD camera (Andor DH-734-18F-03) for the CO-LIF signal. Gating for the Raman camera was provided by a rotating shutter operating at $21000 \mathrm{rpm}$. The stationary and rotating slits were $0.50 \mathrm{~mm}$ and $0.55 \mathrm{~mm}$, respectively, and they were centered at a radius of $63.5 \mathrm{~mm}$, producing a gate width of $3.9 \mu \mathrm{s}$ (FWHM). This high-speed shutter operated in tandem with a low-speed (3000 $\mathrm{rpm}$ ) shutter, placed at the focal plane of the main collection lens, which provided $300 \mu \mathrm{s}$ gating for the Rayleigh camera. A custom-made phase-locked loop (PLL) circuit controlled the two wheels and provided the master timing signals for operation of lasers and cameras.

Crossed-planar Rayleigh imaging (CPRI) from two crossed 355-nm laser sheets that intersected along the multi-scalar probe line, provided the instantaneous 3D flame orientation. The two laser sheets were each at 34 degrees with respect to the burner axial direction. Two Andor (Istar DH312T-18F-E3), intensified, CCD cameras imaged the laser sheets through two CVI UV aplanar lens 
systems (double APMQ, $60 \mathrm{~mm}$ clear aperture, 300 mm working distance) for 1:1 imaging. The cameras and lenses were oriented with their axes orthogonal to the laser sheets to minimize distortions.

Binning of the cameras was performed to improve the signal-to-noise ratio, and the resulting super-pixels were $0.103,0.020,0.101$ and $0.05 \mathrm{~mm}$ along the laser axis, for the Raman, Rayleigh, CO-LIF, and CPRI cameras, respectively. The optical resolution of the system was limited to 0.05$0.06 \mathrm{~mm}$ by the achromatic lenses chosen. The beam diameter, the angle between the flame and the beam, and the blurring effect caused by the flame itself limit the effective spatial resolution. Focusing and alignment of all five cameras was accomplished by placing a target at the object plane and back illuminating the target through a diffuser with light of appropriate wavelength.

\section{Data Analysis}

\subsection{Raman\Rayleigh\CO-LIF data analysis}

The "hybrid" method [40] was used to evaluate the 1D Raman\Rayleigh|CO-LIF data. "Raman channels" were defined on the CCD camera by on-chip binning over assigned spectral regions in addition to the previously mentioned binning in the spatial direction, which divides the 6-mm laser probe volume into 60 "strips". The signal recorded on the Raman camera was background subtracted, normalized by the laser energy, and multiplied by an empirical throughput matrix to obtain the Raman signal vector $S$. The species number density vector $N$ is related to the Raman signal vector $S$ (at given location $\mathrm{x}$ and instantaneous realization) through the matrix $C$ :

$$
S=C(T, x) \cdot N
$$

The signal on each channel contains the Raman response of its associated species (diagonal terms of the $C$-matrix) as well as contributions (cross-talk) from all the other species (off diagonal terms of the $C$-matrix). Most cross-talk contributions are negligible, making the $C$ matrix sparse. All the elements of the $C$-matrix are temperature and strip dependent (to correct for the bowing effect on the CCD image produced by the short focal length spectrometer). The "hybrid" method uses theoretical Raman spectra from the Ramses code [41], to generate a library containing the temperature and strip dependence of the $C$-matrix elements. For species for which Ramses spectra are not available $\left(\mathrm{CH}_{4}\right)$ or crosstalk terms are less accurate $\left(\mathrm{H}_{2} \mathrm{O}\right.$ and $\mathrm{H}_{2}$ onto $\mathrm{O}_{2}$ and $\left.\mathrm{CO}_{2}\right)$, empirical temperature dependences are used. For these species, the strip dependence is neglected, reducing the accuracy of the measurements away from the bowing center, which corresponds to the optical axis of the spectrometer.

Given the signal vector $S$ and the Raman response matrix $C$, the number densities can be obtained by matrix inversion. The process is iterative since the matrix $C$ depends on the temperature that is unknown. An initial temperature is estimated from the Rayleigh signal, then the number densities are computed, and a more accurate temperature is obtained using the computed Rayleigh cross-section. Convergence to within $1 \mathrm{~K}$ typically takes only 3-4 iterations.

The Ramses library provides the temperature and spatial dependencies of the $C$-matrix elements, but empirical calibrations are needed to determine their absolute values. Raman response and crosstalks for $\mathrm{N}_{2}, \mathrm{O}_{2}, \mathrm{H}_{2}$, and $\mathrm{CH}_{4}$ are determined from measurements in jets of air, $\mathrm{H}_{2}$, and $\mathrm{CH}_{4}$, respectively. Measurements in Hencken burner $\mathrm{H}_{2}$-air flames with equivalence ratio $\Phi$ ranging from 0.2 to 1.8 are used to calibrate $\mathrm{H}_{2} \mathrm{O}$ and $\mathrm{H}_{2}$ responses and crosstalks, as well as the crosstalk of $\mathrm{N}_{2}$ on CO. Premixed $\mathrm{CH}_{4}$-air flat-flames with $\Phi$ between 0.8 and 1.3 provide calibration coefficients for $\mathrm{CO}_{2}$ and $\mathrm{CO}$. An optimization algorithm determines the calibration coefficients which minimize the difference between the measured and the predicted concentrations. This new, automated approach is 
faster and more accurate than what was implemented in past works [8, 13, 14]. The predicted values were computed using Chemkin, under the chemical equilibrium assumption. The product temperatures were set to match adiabatic temperatures for the Hencken burner $\mathrm{H}_{2}$-air flames and previous CARS measurements (obtained with the same method of [42]) for the $\mathrm{CH}_{4}$-air flat-flame burner.

Figure 2compares the predicted non-adiabatic equilibrium conditions (lines) with measurements (symbols) in the flat-flame series. The error-bars represent one standard deviation. The temperature agreement is within $20 \mathrm{~K}$, and the standard deviation over 100 single acquisitions is $16 \mathrm{~K}(0.7 \%)$. Concentration measurements are within $0.3 \%$ of the predicted values, showing that the optimization routine performs well. The precision of the measurements changes with the temperature and the concentration measured. Table 2 shows representative standard deviations measured in the premixed $\mathrm{CH}_{4}$-air flat flame. Standard deviations for the $\Phi=1$ premixed $\mathrm{CH}_{4}$-air flame, expressed as percentage of the mean value, are $0.7 \%$ for $\mathrm{N}_{2}, 2 \%$ for $\mathrm{H}_{2} \mathrm{O}$, and $3.2 \%$ for $\mathrm{CO}_{2}$. Standard deviation for $\mathrm{CO}$ and $\mathrm{H}_{2}$ number densities and the $\mathrm{C} / \mathrm{O}$ and $\mathrm{C} / \mathrm{H}$ atom ratios, for the $\Phi=1.29$ premixed $\mathrm{CH}_{4}$-air flame, are $5.3 \%, 7 \%, 3.8 \%$, and $3.1 \%$, respectively.

Calibration data are collected once per test-day and new calibration coefficients are determined. The "repeatability" column of Table 2 shows the average error in the measured scalars, when using calibration coefficients computed from one premixed flame set to process data from different premixed flame sets. The largest variations are in the $\mathrm{O}_{2}$ and $\mathrm{CO}_{2}$ mass fractions, $1.8 \%$ and $1.5 \%$, respectively. We collected Raman/Rayleigh data in room air several times during the test day, to allow frequent re-calibration of the Rayleigh response, $\mathrm{N}_{2}$ and $\mathrm{O}_{2}$ Raman response, and crosstalk of $\mathrm{O}_{2}$ onto $\mathrm{CO}_{2}$. This helps in maintaining high accuracy of temperature and the $\mathrm{N}_{2}$ and $\mathrm{O}_{2}$ mass fractions throughout the test day.

\subsection{CPRI data analysis}

The CPRI provides the instantaneous 3D flame orientation along the line imaging probe volume. Rayleigh images were background subtracted using the mean "dark" image obtained while blocking the laser sheets. Rayleigh images taken in ambient air were used to correct non-uniformities in the camera response, and in the time-averaged laser sheet profile. The CPRI images presented in this work were centered near the interface between products and reactants and the field of view was sufficiently large to contain a region of $\mathrm{N}_{2}$ coflow at room temperature. Non-uniformities of the Rayleigh signal in $\mathrm{N}_{2}$ were caused by shot-to-shot variations in the laser sheet profiles. A normalization curve was determined for each image to provide a uniform Rayleigh signal in the $\mathrm{N}_{2}$ region, and this curve was propagated along the laser direction, to correct for shot-to-shot variations in the laser sheet profile. The Rayleigh images were smoothed using a Gaussian filter with standard deviation proportional to the measured temperature similar to what was done by Frank et al. in [43]. The results from the Raman\Rayleigh $\backslash$ CO-LIF measurements were fed into the CPRI data analysis to determine the local Rayleigh cross section. Since only 1D profiles were available from the Raman measurements, the values of the Rayleigh cross section were then propagated in the direction orthogonal to the direction of propagation of the Raman probe. This is a reasonable approximation in the neighborhood of the 1D probe line, but it gets increasingly worse moving away from the probe line, and as the flame angle increases. The progress variable, $c$, was computed along the 1D probe volume as,

$$
c=\left(T-T_{u}\right) /\left(T_{a d}-T_{u}\right)
$$

with $T, T_{a d}$, and $T_{u}$ being the measured, the adiabatic, and the reactant temperature, respectively. 
Isocontours of the Rayleigh temperature field corresponding to the range $0.15 \leq c \leq 0.85$ were computed using a marching-square algorithm. The procedure to extract the flame normal from the two temperature isocontours was the same as described in [13]. The isocontour coordinates were indexed along the flame front $s$. A 10-point cubic spline was fitted through the isocontour in the neighborhood of the $1 \mathrm{D}$ probe line. The polynomials were differentiated to determine the tangent to the flame front at the intersection with the 1D probe line. Knowing the angle between the two crossed planar images, it is possible to determine the flame front tangents $\left(\boldsymbol{t}_{1}, \boldsymbol{t}_{2}\right)$ in the laboratory reference frame and obtain the instantaneous 3D normal as cross products of the two tangents;

$$
\boldsymbol{n}=\boldsymbol{t}_{\mathbf{1}} \times \boldsymbol{t}_{\mathbf{2}}=\left(\dot{x}_{1} \boldsymbol{i}+\dot{y}_{1} \sin \Omega \boldsymbol{j}+\dot{y}_{1} \cos \Omega \boldsymbol{k}\right) \times\left(\dot{x}_{2} \boldsymbol{i}-\dot{y}_{2} \sin \Omega \boldsymbol{j}+\dot{y}_{2} \cos \Omega \boldsymbol{k}\right)
$$

with $\boldsymbol{i}, \boldsymbol{j}, \boldsymbol{k}$ the unit vectors in the laboratory reference frame, $\Omega$ the angle between the laser sheets and the vertical direction $(\boldsymbol{k})$. The angle $\theta$ between the flame normal and the 1D line measurements axis $x$ was obtained as:

$$
\theta=\arccos \left(\frac{\boldsymbol{n} \cdot \boldsymbol{i}}{|\boldsymbol{n}|}\right)
$$

The angle $\theta$ here reported is computed for $c=0.5$, by cubic interpolation of angles measured in the range $0.4 \leq c \leq 0.6$. Values of the angle $\theta$ computed for $c=0.7$ are within 1.5 degrees of the values here reported.

Knowledge of the flame-front angle allows computing the 3D progress variable gradient, the scalar dissipation, and the flame thickness. The projection of the progress variable gradient along the radial direction $\frac{\partial c}{\partial x}$ is computed from the oversampled Rayleigh temperature measurements (20 $\mu \mathrm{m}$ spacing), applying a 21-point smooth, noise-robust, differentiation scheme [44]. The optical resolution of the system $(\sim 60 \mu \mathrm{m})$ degrades with increasing flame angle because of the beam diameter, affecting the accuracy of the gradient measurements. Sweeney et al. [13] determine a local resolution correction factor, based on a series of laminar calculations, to reduce the errors caused by the differentiation scheme. In this work no correction factor was implemented, but when comparing to laminar calculations, we down-sampled the numerical results to the optical resolution and used the same differentiation scheme to compute the gradients.

The 3D gradient of temperature or progress variables can be obtained from the 1D value computed along the measurement axis divided by the cosine of the flame angle $\theta$

$$
\nabla c=\frac{\partial c}{\partial n}=\frac{\partial c}{\partial x} / \cos (\theta)
$$

The flame thickness $\delta_{T}$ was determined using the maximum gradient method

$$
\delta_{T}=1 / \max (|\nabla c|)
$$

The scalar dissipation rate of the progress variable $c$ is defined as:

$$
\chi_{c}(T, \phi)=\alpha(T, \phi)|\nabla c| \cdot|\nabla c|
$$

where the thermal diffusivity $\alpha(T, \phi)$ was evaluated by interpolating to the local temperature and equivalence ratio values from a lookup table of thermal diffusivities from laminar unstrained calculations.

As shown in Ref. [13,45] the uncertainties in the 3D gradients, and therefore in the flame thickness and in the scalar dissipation rate, increase as the flame angle increases. Fig. 3 shows the flame thickness as function of the flame angle measured in the $\Phi=0.75$, low-speed bluff-body stabilized flame. For angles above 50 degrees, the flame thickness decreases, suggesting errors in the 
measurements, hence we chose 45 degrees as the maximum allowed flame angle. Single shot measurements, for which a flame-front angle above this threshold was measured, were discarded ( $\sim 12 \%$ for the case in Fig. 3, the largest value recorded in this test). Rejection of the large angle entries can potentially introduce a bias in the measurements.

\subsection{Vertical Flame validation}

To assess the performance of the diagnostic system, measurements in a 'vertical', nearly planar, unstrained premixed flame, described in [8], are compared with a laminar calculation performed with Chemkin PRO for a freely propagating premixed $\mathrm{CH}_{4} /$ air flame, using GRI Mech 3.0 and multi-component transport with the Soret effect included. Fig. 4 shows spatial profiles of the mass fraction of major species, the $\mathrm{C} / \mathrm{H}$ and $\mathrm{C} / \mathrm{O}$ atom ratios, and the temperature. The scalar profiles are projected onto the direction normal to the flame-front, to remove errors due to the flame orientation, such as flame thickening and gradient smoothing. To facilitate visual comparisons, the spatial profiles are shifted so that the progress variable $c=0.5$ is at the origin. The plots show excellent agreement between the experimental measurements and the predicted values, with differences within $1 \%$ for the mass fractions, the temperature, and the atom ratios in the reactants and the products. For the atom ratios, discrepancies up to $2.5 \%$ are measured near the dip. $\mathrm{CO}$ and $\mathrm{H}_{2}$ values at their peak location and are $1.1 \%$ and $7.8 \%$ smaller than the predicted values. Note that $\mathrm{H}_{2}$, at its peak value accounts for only $0.5 \%$ of the total mole fraction.

The mean value of the measured flame angle $\theta$ is 5.9 with a 4.7 degrees standard deviation. The reported standard deviation is indicative of actual fluctuations of the laminar flame angle, not limitations in the accuracy of the angle measurement. This is supported by examining changes in the conditional standard deviation of any measured scalar after projecting it onto the flame normal. We observed conditional standard deviations up to $70 \%$ smaller than before the projection, indicating that shot-to-shot variations in the measured flame angle account for actual fluctuations in the flame orientation.

Figure 5compares the measured 3D progress variable gradient and scalar dissipation to the laminar calculations, downsampled to the experimental spatial resolution to remove discrepancies from the differentiation scheme. The measured and computed profiles differ by up to $8 \%$ on the reactant side, but the agreement improves on the product side. The disagreement on the peak gradient and scalar dissipation is below $4 \%$. The measurements overestimate the flame thickness, $0.75 \mathrm{~mm}$, by $\sim 3.5 \%$ with respect to the predicted value. We repeated measurements in the vertical flame once for each test day, to validate the calibration process. Results presented here are typical.

\section{Results and Discussion}

\subsection{Fuel-lean bluff-body stabilized $\mathrm{CH}_{4}$-air flames}

Figure 6 shows conditional mean profiles of $\mathrm{C} / \mathrm{H}$ and $\mathrm{C} / \mathrm{O}$ atom ratios and, $\mathrm{CO}, \mathrm{CO}_{2}, \mathrm{H}_{2}$, and $\mathrm{O}_{2}$ mass fractions as functions of the temperature measured in the bluff-body stabilized flame with nominal equivalence ratio $\Phi=0.75,10 \mathrm{~mm}$ from the surface, and with a ratio of bulk velocity to laminar flame speed $\left(U_{b} / S_{L}\right)$ of 5.2 (blue), 31 (green), and 52 (red). Conditional statistics are based on 900 instantaneous, 6-mm profiles (each containing 60 samples), with a minimum of 50 samples for each conditional temperature. The error bars on the $U_{b} / S_{L}=52$ curve represent one standard deviation (conditional). The experimental profiles are compared to a laminar unstrained premixed 
flame calculation at $\Phi=0.75$ (black dashed line) performed using Chemkin PRO with the GRI Mech 3.0, including the Soret effect and multi-component transport.

At the lowest velocity the scalar structure agrees well (within 10\%) with the Chemkin 1D calculation, and the profiles have a similar shape. In particular, the $\mathrm{C} / \mathrm{H}$ and $\mathrm{C} / \mathrm{O}$ peaks are $1.9 \%$ and $0.9 \%$ larger than the calculated values, well within the uncertainty of the measurements. We observe larger discrepancies, up to $4.5 \%$, in the atom ratios at intermediate temperatures. Katta [15] observed a similar discrepancy, comparing his UNICORN 2D calculations to Chemkin 1D profiles and stated that 2D effects, ignored in Chemkin, were partly responsible for the difference.

Increasing the bulk velocity of the reactants, effects of preferential diffusion similar to those reported in $[8,14]$ are observed. The $\mathrm{C} / \mathrm{H}$ and $\mathrm{C} / \mathrm{O}$ atom ratios increase with the reactant velocity, such that the peak values for the highest velocity considered $\left(U_{b} / S_{L}=52\right)$ are $\sim 15 \%$ higher than for the lowest velocity. Similarly, the $\mathrm{CO}_{2}$ mass fraction increases with increasing bulk velocity, while $\mathrm{H}_{2}$ and $\mathrm{O}_{2}$ decrease, as indicated by the direction of the arrows in Fig. 6. No significant changes are detected in the $\mathrm{H}_{2} \mathrm{O}$ and $\mathrm{CH}_{4}$ mass fractions, and accordingly, these are not shown in Fig. 6.

Scalar profiles for the $U_{b} / S_{L}=52$ case have the $\mathrm{CO}_{2}$ and $\mathrm{O}_{2}$ mass fractions following a nearly linear trend with temperature, characteristic of highly strained flames. The red dashed curves of Fig. 6 show the scalar structure of a highly strained laminar flame from opposed flow calculations (strain rate $\sim 3500 \mathrm{~s}^{-1}$ ). The product state and the strain rate were set to match the measured composition on the centerline and the $\mathrm{CO}_{2}$ profile against temperature, $10 \mathrm{~mm}$ from the bluff-body surface. We used Chemkin PRO with the GRI Mech 3.0, including the Soret effect and multi-component transport to perform the simulation. The agreement is fairly good (within 7\%) with the exception of CO, which is higher in the experiment. The comparison shows that strain plays a role in the shape of the scalar structures as the bulk reactant velocity is increased. The results are consistent with previous measurements [14].

Figure 7 shows conditional mean mass fractions and selected atom ratios, measured in the bluffbody stabilized flame with nominal $\Phi=0.75$ and $U_{b} / S_{L}=52$, at axial distances from the bluff-body of 5 (blue), 7.5 (green), 10.0 (red), 12.5 (black), 15 (cyan), and $20 \mathrm{~mm}$ (purple), compared to the laminar unstrained and highly strained Chemkin calculations. The strongest preferential diffusion effects are observed closest to the bluff-body surface. Increasing the distance from the burner (direction of the arrows in Fig. 7) the preferential transport effects are mitigated. The atom ratios and the $\mathrm{CO}_{2}$ mass fraction decrease, the $\mathrm{H}_{2}, \mathrm{O}_{2}$, and $\mathrm{CO}$ mass fractions increase, and the profiles become less linear and closer to the unstrained profiles (black dashed curve). Results are qualitatively similar to the calculation from Katta et al. (see Fig. 2 in [15]).

Bluff-body stabilized flames are characterized by a low-speed recirculation region adjacent to a higher speed reactant flow. Due to preferential diffusion, $\mathrm{H}_{2} \mathrm{O}$ and $\mathrm{H}_{2}$ are transported farther into the reactant side of the flame surface compared to $\mathrm{CO}_{2}$ and $\mathrm{CO}$. The peak in $\mathrm{H}_{2} \mathrm{O}$ production is also closer to the reactants than that of $\mathrm{CO}_{2}$ as shown in Fig.10 of [8].The higher speed flow on the reactant side siphons the $\mathrm{H}_{2} \mathrm{O}$ and $\mathrm{H}_{2}$ out of the products. Since the gas in the recirculation region has a longer residence time, the effect is integrated over time, causing a significant increase in the $\mathrm{C} / \mathrm{H}$ and $\mathrm{C} / \mathrm{O}$ atom ratios. Based on this mechanism, preferential diffusion effects are enhanced in the presence of a strong velocity gradient across the flame brush.

Flowfield measurements in bluff-body flames stabilized on the Cambridge burner [10] show that the recirculation region bends inward as the distance from the burner is increased and becomes more elongated as the bulk reactants velocity is increased. The burner used for this study is a simplified version of the Cambridge burner, and conditions of the present $U_{b} / S_{L}=31$ flames are similar to the premixed, non-swirling case reported in [10]. Therefore, we expect a similar behavior of the 
recirculation region in the flames object of this study. Figure 8 shows the mean flame-front angle from CPRI measurements, for the low- and high-speed cases, as functions of the distance from the burner. The flame-front angle decreases with the reactants bulk velocity and increases with the distance from the burner. In addition, as observed by Zhou [10], the recirculation zone is more elongated at higher velocities. Figure 9 offers a sketch of the flame brush and of the recirculation zone at low and high speed. The sketch is qualitative and exaggerates the difference between the two conditions for the purpose of illustration. At low velocities and sufficient distance from the surface, the flame brush is decoupled from the recirculation zone, and no significant enhancements of the preferential transport effects are expected. This is the case for the $U_{b} / S_{L}=5.2$ case, $10 \mathrm{~mm}$ from the surface, where no preferential transport effects were measured. As the bulk reactant velocity increases, the flame-front angle is reduced, pushing the flame against the more elongated recirculation zone. In these conditions the preferential diffusion is coupled with the velocity gradient, causing the strong changes in the $\mathrm{C} / \mathrm{H}$ and $\mathrm{C} / \mathrm{O}$ ratios observed. For given velocity of the reactants, the flame-front angle increases with increasing distance from the burner; the flame bends outward, while the recirculation zone bends inward. Increasing the distance from the bluff-body surface, the separation of the flame-front from the recirculation zone becomes wider. Therefore, the preferential transport effects are smaller, as observed in the experimental data of Fig. 7 and in numerical simulation by Katta et al. [15].

The plots of Fig. 6 and Fig. 7 are limited to a 6-mm region centered on the flame-front, so they do not provide information on other regions of the flow, such as the center of the recirculation zone. Figure 10 shows radial profiles of $\mathrm{C} / \mathrm{H}$ ratio, $\mathrm{CO}_{2}, \mathrm{H}_{2} \mathrm{O}$, and temperature for the fuel-lean case $(\Phi=0.75)$ at the three velocities considered $\left(U_{b} / S_{L}=5.2\right.$ left column, $U_{b} / S_{L}=31$ center column, and $U_{b} / S_{L}=52$ right column), at distances from the bluff-body ranging from $5 \mathrm{~mm}$ (blue curves) to $20 \mathrm{~mm}$ (purple curves). Since the radial direction does not match the flame-front normal, comparisons of the measured profiles with the laminar calculations are not provided. At the lowest speed, $5 \mathrm{~mm}$ from the base (blue curve, left column), preferential diffusion effects are small but detectable. There are peaks in $\mathrm{C} / \mathrm{H}$ ratio near the flame front, but in addition there are peaks of $\mathrm{CO}_{2}$ and $\mathrm{C} / \mathrm{H}$ and a dip in temperature at the centerline. Laminar calculations by Katta et al. [15] show $\mathrm{CO}_{2}$ and $\mathrm{C} / \mathrm{H}$ profiles that are qualitatively similar to the ones we observed experimentally. Figure 1 from [15] shows the streamlines superimposed on $\mathrm{C} / \mathrm{H}$ and $\mathrm{CO}_{2}$ mole fraction contour maps from the laminar calculation and it is very helpful in understanding the profiles observed experimentally in the present flames. Even at low speed, there is a significant gradient of velocity at the corner between the bluff-body surface (where the velocity is zero) and the reactant flow. This is also the location where the flame is attached. Therefore, significant preferential transport effects are present. Convection of products from this region to the centerline, following streamlines illustrated in Fig. 9, or in Fig.1 of [15], causes the peaks in the $\mathrm{C} / \mathrm{H}$ and $\mathrm{CO}_{2}$ and the dip in temperature. Farther downstream (green, red, and black curves, corresponding to 7.5, 10.0, and $12.5 \mathrm{~mm}$ from the surface), the $\mathrm{C} / \mathrm{H}$ peak near the flame brush becomes weaker and moves outward, as a consequence of the flame opening up and decoupling from the recirculation zone. Still farther downstream there is only the centerline peak in $\mathrm{C} / \mathrm{H}$, which decays slowly with distance as a remnant of preferential transport effects in the near field. No alterations of the $\mathrm{C} / \mathrm{H}$ ratio can be detected near the flame front. At large values of $x$, measurements are in the $\mathrm{N}_{2}$ coflow, where both $\mathrm{C}$ and $\mathrm{H}$ are not present, and the large values of $\mathrm{C} / \mathrm{H}$ are determined by small residuals in the species measurements.

The center and right columns provide profiles of $\mathrm{C} / \mathrm{H}, \mathrm{CO}_{2}, \mathrm{H}_{2} \mathrm{O}$ and temperature for the intermediate and high-speed cases, respectively. At $5 \mathrm{~mm}$ from the burner the $\mathrm{C} / \mathrm{H}$ ratios for these two cases are the same. Measurements $5 \mathrm{~mm}$ from the bluff-body surface, show that increasing the 
velocity from $U_{b} / S_{L}=31$ to $U_{b} / S_{L}=52$ does not produce any change in the amplitude of the preferential transport effects. The presence of a limiting state was already observed by Dunn [14] at $10 \mathrm{~mm}$ from the surface, at higher velocities. At increasing distance from the surface the two cases differentiate, with the preferential diffusion effects disappearing sooner for the intermediate case. It is also interesting to note that the $\mathrm{C} / \mathrm{H}$ atom ratio at the centerline does not vary significantly between the intermediate and high-speed cases. As pointed out for the low speed case, the centerline behavior is dominated by the preferential transport effects near the corner. Because of the presence of a limiting state, we expect the radial profiles of the two flames close to the surface to be very similar (as they are at $5 \mathrm{~mm}$ ). Therefore, their $\mathrm{C} / \mathrm{H}$ ratios at the centerline are also similar.

With knowledge of the flame-front angle, we can project the instantaneous radial profiles onto the flame-normal coordinate, with the origin corresponding to $c=0.5$, in order to compare directly to laminar flame calculations in the spatial domain, rather than the temperature domain. Spatial profiles allow studying the effects of strain and turbulence on the scalar structure of the flame. The top portion of Fig. 11 shows the temperature and $\mathrm{H}_{2} \mathrm{O}$ mass fraction profiles for the $\Phi=0.75$ case at $U_{b} / S_{L}=5.2$ (low speed case), $10 \mathrm{~mm}$ from the surface, plotted against the radial direction and compared to the laminar calculations. The red curve is the mean profile, the blue are three randomly selected instantaneous profiles. Both the temperature and the $\mathrm{H}_{2} \mathrm{O}$ profiles appear thicker than the laminar calculation, and the apparent thickness changes between shots. The middle portion of Fig. 11 shows the same three single shots projected along the flame-normal direction, along with the mean of all projected single-shot profiles. The agreement with the laminar calculation is now excellent, and the shot-to-shot variation is no longer detectable. This result further validates the CPRI angle measurements and suggests that the fluctuations in the angle measurements ( 8.9 degrees) are actual flame fluctuations and they are not caused by the poor precision of the diagnostic technique. The plots at the bottom of Fig. 11 show the projected profiles for the $U_{b} / S_{L}=52$ case, 10 $\mathrm{mm}$ from the surface. The mean and three single shots are plotted and compared to the unstrained and highly strained flame calculations. The single-shot profiles do not collapse on the mean as in the low speed case, and the mean profiles rise more slowly than in the computation (thicker flame). In particular, stronger variations are present in the pre-heat zone.

Figure 12 shows the three dimensional progress variable gradient and the 3D scalar dissipation rate (Eqn. 7) for the fuel-lean case at the three velocities considered $\left(U_{b} / S_{L}=5.5\right.$ on the left, $U_{b} / S_{L}=31$ in the center, $U_{b} / S_{L}=52$ on the right) for three distances from the burner ( $10 \mathrm{~mm}$ red, $12.5 \mathrm{~mm}$ black, 15 $\mathrm{mm}$ cyan). At the lowest speed both the gradient and the scalar dissipation show good agreement with the unstrained laminar calculation. The progress variable gradient decreases with increasing velocity and large discrepancies appear, especially in the pre-heat zone, as already observed in the spatial profile plots. The flame-front thickness is here expressed as the inverse of the maximum of the progress variable gradient. The measured flame thickness $(0.63 \mathrm{~mm})$ is $3.4 \%$ smaller than the values computed for the unstrained flame calculation, a discrepancy that is within the accuracy of the measurement (based on the vertical flame data). For the high-speed case the mean flame-front thickness is $0.71 \mathrm{~mm}, \sim 10 \%$ larger than the unstrained flame thickness and $25 \%$ larger than the strained flame value. Changes with the axial distance are not significant.

Previously we observed that, as the bulk velocity of the reactants increases, the scalar profiles in temperature space show an increasing effect of strain. The opposed-flow laminar calculations show that strain produces a thinning of the flame, but the experiments show a thicker flame for conditions matching high strain profiles in the temperature space. The spatial profiles of Fig. 11 and the progress variable gradient plots of Fig. 12 show a thickening of the pre-heat zone but no significant changes in the rest of the flame. This behavior is consistent with a thin reaction zone regime, in 
which turbulent eddies can penetrate the pre-heat zone and increase the mixing process, leading to thicker flame brush. The large scale flow straining produces a thinning of the flame (as shown in the laminar strained calculation), mitigating the thickening due to the turbulence. At high velocity, the spatial structure of the flame is determined by these two competing mechanisms. Experimental measurements of the flowfield, or DNS calculations are desirable to confirm the proposed explanation. The progress variable scalar dissipation for the low-speed case, agrees well with the unstrained laminar calculation, except for the peak value that is $\sim 20 \%$ higher. The medium and highspeed cases show a scalar dissipation rate that is roughly half of the rate determined from unstrained calculations and one third of the rate from strained flame calculation. There is no significant difference between the intermediate and high-speed cases, and there is no dependence on the distance from the burner. Single-shot measurement are provided for the $\mathrm{z}=10 \mathrm{~mm}$ case (scatter points in Fig. 12). The low-speed single-shot measurements show a narrow range of variation around the mean (6\% standard deviation), representative of the precision of the measurement. The variance of the scalar dissipation increases approaching $c=1$ because of the increase in photon noise in the Rayleigh measurements. For the high speed case, the standard deviation is much larger $(21.5 \%$ at the mean peak location and up to $43 \%$ in the pre-heat zone), suggesting a broad distribution of flamefronts. These results are consistent with the intermittent nature of the flame-turbulent eddies interaction. When the flame-front interacts with eddies smaller than the pre-heat zone the flame structure becomes thicker and the scalar dissipation is reduced. Otherwise, the flame structure is flamelet like, but thinner than the freely propagating counterpart because of the strain.

\subsection{Fuel-rich bluff-body stabilized flame}

This section presents the results from measurements in the fuel-rich bluff-body flames $(\Phi=1.23)$. The analysis provided for the fuel-lean cases is repeated for the rich flames, and the effects of the higher equivalence ratio are discussed. Figure 13 shows conditional mean profiles of $\mathrm{C} / \mathrm{H}$ and $\mathrm{C} / \mathrm{O}$ atom ratios and $\mathrm{CH}_{4}, \mathrm{CO}, \mathrm{CO}_{2}, \mathrm{H}_{2}, \mathrm{H}_{2} \mathrm{O}$, and $\mathrm{O}_{2}$ mass fractions as functions of the temperature measured in the bluff-body stabilized flame with nominal equivalence ratio $\Phi=1.23,10 \mathrm{~mm}$ from the surface, and with a ratio of bulk velocity to laminar flame speed of 5.5 (blue), 9.3 (green), and 26 (red). Statistics are based on 900 instantaneous, 6-mm profiles (each containing 60 samples), with a minimum of 50 samples for each conditional temperature. The experimental profiles are compared to a laminar unstrained premixed flame calculation at $\Phi=1.23$ (black dashed line) performed using Chemkin PRO, with the GRI Mech 3.0, including the Soret effect and multi-component transport. The red dashed line shows the results of a highly strained opposed flow calculation, with the product state matching the experimental results for $U_{b} / S_{L}=26$, and $10 \mathrm{~mm}$ from the bluff-body surface. Figure 14 shows the evolution of scalar profiles with increasing distance from the bluff-body surface in the highest velocity $\left(\left(U_{b} / S_{L}=26\right)\right.$ fuel-rich flame.

Comparison of Figs. 13 and 14 with the corresponding fuel-lean results in Figs. 6 and 7 leads to several observations. As in the fuel-lean case, the preferential transport effects become stronger with increasing bulk velocity of the reactants, and the scalar profiles resemble those found in highly strained flames. Overall the preferential transport effects are stronger in the fuel-rich flames than in the fuel-lean flames. At the lowest velocity the preferential transport effects are already significant, distorting the scalar profiles from what is observed in laminar unstrained fuel-rich flames. At the highest reactants velocity, the peak $\mathrm{C} / \mathrm{H}$ ratio is $0.36,35 \%$ larger than the Chemkin predicted value

for an unstrained flame, where in the fuel-lean case it was $18 \%$ higher. Figure 14 shows that preferential transport effects are stronger near the bluff-body surface, as already observed in the fuel-lean flame. However, for given reactant velocity, changes with the 
distance are stronger in the fuel-rich case. For the high speed case shown in Fig. 14, increasing the distance from the surface from 5 to $20 \mathrm{~mm}$, the $\mathrm{C} / \mathrm{H}$ ratio varies by $12 \%$ in the lean flame, by $26.5 \%$ in the rich flame.

These results are consistent with the flame angle measurements (blue line in Fig. 8). For rich flames the flame-front angle is systematically smaller than for lean flames. Therefore, there is better coupling between the flame-front and the recirculation zone, with the consequent enhancement of the preferential transport effects. The stronger dependence of the preferential transport effects with the distance from the bluff-body is also consistent with larger flame-front angle variation; the flamefront angle increases from 17 to 25 degrees moving downstream from $\mathrm{z}=10 \mathrm{~mm}$ to $\mathrm{z}=20 \mathrm{~mm}$, where in the fuel-lean case the variation was from 24 to 29 degrees. The presence of higher levels of $\mathrm{H}_{2}$ and $\mathrm{H}_{2} \mathrm{O}$ diffusing toward the fast reactants also contributes to the stronger preferential transport effects.

Figure 15 shows radial profiles of $\mathrm{C} / \mathrm{H}$ ratio, $\mathrm{CO}_{2}, \mathrm{H}_{2} \mathrm{O}$, and temperature for the fuel-rich case $(\Phi=1.23)$ at the three velocities considered, at distances from the bluff-body ranging from $5 \mathrm{~mm}$ (blue curves) to $20 \mathrm{~mm}$ (purple curve). At the lowest speed $\left(U_{b} / S_{L}=5.5\right.$, left column) we observe at all axial distances, a peak of $\mathrm{C} / \mathrm{H}$ ratio and $\mathrm{CO}_{2}$ and a dip in the $\mathrm{H}_{2} \mathrm{O}$ and temperature along the centerline. The flame is attached near the bluff-body corner, and a velocity gradient is present. Therefore, strong preferential transport effects are present. Gases from this region are convected to the centerline and are responsible for the peaks and dips observed. The $\mathrm{C} / \mathrm{H}$ peak near the flame front, indicative of preferential transport, does not appear, implying that at this low velocity and large flame angle, preferential transport effects are already not significant $5 \mathrm{~mm}$ above the bluffbody surface. As in the fuel-lean case, at the bluff-body corner, the fuel-rich flame-front is adjacent to the recirculation zone. Therefore, preferential diffusion is coupled to a strong velocity gradient, generating large atom imbalances that are convected to the centerline, as illustrated by Fig. 9. Since $\mathrm{H}_{2}$ and $\mathrm{H}_{2} \mathrm{O}$ preferential diffusion also contributes to generate the imbalance, the $\mathrm{C} / \mathrm{H}$ ratio is larger than observed in the fuel-lean case. The flame front angle is roughly the same observed in the fuellean case, but the lack of preferential transport effects suggest that the recirculation region is smaller, bending inward and closing earlier than the fuel-lean counterpart. Zhou et al. [10] documented a similar effect in their non-swirling bluff-body flames, where the recirculation zone was more compact in the case with $\Phi=1.125$ in the inner annular flow than with $\Phi=0.75$, both having bulk reactant velocity of $8.3 \mathrm{~m} / \mathrm{s}$.

The intermediate velocity case $\left(U_{b} / S_{L}=9.3\right.$ central column) shows large peaks of $\mathrm{C} / \mathrm{H}$ near the flame-front up to $7.5 \mathrm{~mm}$. Downstream of this location the $\mathrm{C} / \mathrm{H}$ ratio peaks on the centerline, signaling a decoupling of the flame-front and the recirculation zone, with only products from regions closer to the bluff-body surface sustaining the atom imbalance. Changes with axial distance in all the quantities plotted are much more dramatic than in the fuel-lean case, especially for $\mathrm{H}_{2} \mathrm{O}$ and temperature. At higher speed the flame becomes more vertical and the recirculation region more elongated. The coupling between the recirculation zone and the flame-front is maintained up to 20 $\mathrm{mm}$ from the surface, as shown by the $\mathrm{C} / \mathrm{H}$ peaks near the flame-front. The centerline $\mathrm{C} / \mathrm{H}$ ratio decreases with distance, but slower than the $\mathrm{C} / \mathrm{H}$ peaks. It is interesting to notice that $5 \mathrm{~mm}$ from the surface the peak values of $\mathrm{C} / \mathrm{H}$ ratio are the same for both medium and high speed, which is consistent with the existence of a limiting state in the evolution of preferential transport effects with increasing velocity.

The top portion of Fig. 16 shows the temperature and $\mathrm{H}_{2} \mathrm{O}$ mass fraction profiles projected along the flame normal direction for the fuel-rich case, $10 \mathrm{~mm}$ from the bluff-body surface, for the three velocities considered. As in the fuel-lean case (Fig. 11), the origin corresponds to $c=0.5$ in each 
instantaneous profile. The experimental profiles are compared to the unstrained and highly strained calculations. At low speed there is a fairly good agreement with the unstrained calculation, although the measured flame appears slightly thicker. As the velocity increases the flame thickness becomes larger. Changes are not limited to the preheat zone, but they affect the entire flame structure. The temperature in the products also decreases as the velocity increases because of the higher strain. The measured mean flame thickness for $U_{b} / S_{L}=26,10 \mathrm{~mm}$ from the bluff-body is $1.35 \mathrm{~mm}, \sim 2.5$ times larger than the unstrained laminar value. Opposed flow laminar calculations in fuel-rich flames show a broadening of the flame with the strain, as opposed to the fuel-lean case (already observed by Chen et al. in [30]). Therefore, in this flame both strain and small scale turbulent eddies contribute to the broadening of the flame.

The lower portion of Fig. 16 shows results for $U_{b} / S_{L}=26$ for distances from the bluff-body surface ranging from 10 to $20 \mathrm{~mm}$. As the distance from the surface increases from 10 to $15 \mathrm{~mm}$, the flame thickness decreases from $1.35 \mathrm{~mm}$ to $0.85 \mathrm{~mm}$, a $37 \%$ change. In the fuel-lean flame no significant changes with the distance were observed. Figure 14Fig. 14 shows a stronger effect of strain closer to the surface. For fuel-rich mixtures, higher strain corresponds to a broader flame-front, so this is consistent with thicker flames near the surface.

Figure 17 shows the three dimensional progress variable gradient and the 3D temperature scalar dissipation for the fuel-rich case at the three velocities considered at various distances from the surface. At low speed, the 3D gradient and temperature scalar dissipation rate resemble the unstrained laminar calculations, and there are no significant variations with distance from the burner. As the bulk reactant velocity increases the profiles depart from the unstrained calculation. For moderate values of reactant velocity only the pre-heat zone is affected, but good agreement with the freely propagating laminar calculation is kept in the reaction layer. At the highest velocity, as already observed in the spatial profiles of Fig. 16, the entire flame structure is affected. Measurements taken at $10 \mathrm{~mm}$ from the surface show progress variable gradient and scalar dissipation profiles qualitatively closer to the strained flame calculation, but with much reduced amplitude because of the thickening effect of turbulence within the flame. In particular, the peak scalar dissipation for the $U_{b} / S_{L}=26$ case at $10 \mathrm{~mm}$ from the surface being only $1 / 20^{\text {th }}$ of that predicted from unstrained laminar calculations.

\section{Conclusions}

Bluff-body stabilized, premixed $\mathrm{CH}_{4}$-air flames with two equivalence ratios $(\Phi=0.75$ and 1.23$)$, and varying reactant flow velocities have been investigated using Raman/Rayleigh/CO-LIF for instantaneous temperature and major species concentration measurements, and crossed planar Rayleigh imaging for instantaneous flame-front orientation measurements. Flame thickness, progress variable gradients, and scalar dissipation rates were derived from the measurements. The measurement technique was validated in a freely propagating laminar flame, and the accuracy and precision of the diagnostics were discussed. Experimental data were collected at six axial locations at distances ranging from $5 \mathrm{~mm}$ to $20 \mathrm{~mm}$ from the bluff-body surface. The dataset provides better understanding of the effects of shear and preferential diffusion on the flame structure in the bluffbody configuration. The main findings are summarized below.

- When the flame brush is in proximity of the recirculation region, preferential diffusion causes an atom imbalance between products and reactants. $\mathrm{C} / \mathrm{H}$ atom ratios up to $36 \%$ larger than laminar calculations were measured. 
- The $\mathrm{C} / \mathrm{H}$ and $\mathrm{C} / \mathrm{O}$ ratios become larger with increasing reactant velocity, contrary to the common assumption that preferential diffusion effects become weaker with increasing Reynolds number.

- The measured $\mathrm{C} / \mathrm{H}$ and $\mathrm{C} / \mathrm{O}$ ratios are greatest close to the bluff-body surface, in agreement with previous numerical calculations.

- It was hypothesized that preferential transport effects are enhanced when the flame front is next to the recirculation zone. Flame orientation measurements are in agreement with this proposed mechanism. At higher velocities, or closer to the surface, the flame angle is smaller, the flame-front is closer to the recirculation region, and higher values of the atom ratios are observed.

- Comparisons between the measurements and highly strained laminar calculation show that strain plays an increasingly important role in shaping the flame structure as the velocity of the reactants increase or the distance from the bluff-body decreases.

- Measurements show a thickening of the flame with increasing bulk reactant velocity and decreasing distance from the bluff-body surface.

- In the fuel-lean turbulent flames the measured mean flame thickness is only slightly (up to $10 \%$ ) larger than that calculated for a laminar freely-propagating flame. This thickening is believed to be caused by small scale eddies, with size smaller than the flame thickness, penetrating the preheat zone and carrying hot products toward the reactants. No changes were observed within the reaction layer. This thickening effect of turbulence is mitigated by the thinning effect of the mean strain.

- In fuel-rich premixed flames both the strain and turbulence contribute to the thickening of the flame, and we measured mean thickness up to 2.5 times larger than the thickness of a freely propagating flame. At the highest velocities, changes to the spatial structure are not limited to the preheat zone, but affect the entire flame structure.

- In fuel-lean premixed flames the scalar dissipation rate decreases with increasing bulk reactant velocity, with peak values down to half that from a laminar freely propagating flame calculation. These changes are limited to the preheat zone of the fuel-lean flames.

- In fuel-rich premixed flames, large reductions of the scalar dissipation rate were observed with increasing velocity of the reactants or decreasing distance from the bluff-body surface. Peak dissipation values 20 times smaller than predicted by laminar calculations were observed. Further experimental and numerical investigations will be helpful in determining the physical mechanism responsible for the flame thickening and the large reduction in scalar dissipation observed in rich flames. Measurements of velocity and strain from particle image velocimetry (PIV), and measurements of the heat release such as the product of $\mathrm{CO}$ and $\mathrm{OH}$, would provide further insight. DNS simulations are desirable to fully understand the mechanism driving the flame thickening and the observed difference between fuel lean and fuel rich flames.

\section{Acknowledgements}

This research was funded by the Division of Chemical Sciences, Geosciences and Biosciences, Office of Basic Energy Sciences, US Department of Energy. Sandia National Laboratories is a multiprogram laboratory operated by Sandia Corporation, a Lockheed Martin Company, for the United States Department of Energy under contract DE-AC04-94-AL85000. Contributions by Bob Harmon in support of these experiments are gratefully acknowledged. 


\section{References}

[1] K. Liu, S.B. Pope, D.A. Caughey, Combustion and Flame, 141 (2005) 89-117.

[2] D. Most, F. Dinkelacker, A. Leipertz, Proceedings of the Combustion Institute, 29 (2002) 1801-1808.

[3] G. Hartung, J. Hult, C.F. Kaminski, J.W. Rogerson, N. Swaminathan, Physics of Fluids (1994-present), 20 (2008) -.

[4] S.P. Nandula, R.W. Pitz, R.S. Barlow, Fiechtner, Rayleigh/Raman/LIF measurements in a turbulent lean premixed combustor, presented at AIAA 34th Aerospace Sciences Meeting and Exhibit,Reno, NV, Jan 15-18, 1996, 1996, 68.

[5] C. Schneider, A. Dreizler, J. Janicka, Flow Turbulence Combust, 74 (2005) 103-127.

[6] W. Meier, O. Keck, B. Noll, O. Kunz, W. Stricker, Appl Phys B, 71 (2000) 725-731.

[7] M.A. Gregor, F. Seffrin, F. Fuest, D. Geyer, A. Dreizler, Proceedings of the Combustion Institute, 32 (2009) 17391746.

[8] R.S. Barlow, M.J. Dunn, M.S. Sweeney, S. Hochgreb, Combustion and Flame, 159 (2012) 2563-2575.

[9] M.S. Sweeney, S. Hochgreb, M.J. Dunn, R.S. Barlow, Combustion and Flame, 159 (2012) 2896-2911.

[10] R. Zhou, S. Balusamy, M.S. Sweeney, R.S. Barlow, S. Hochgreb, Combustion and Flame, 160 (2013) 2017-2028.

[11] Y.-C. Chen, N. Peters, G.A. Schneemann, N. Wruck, U. Renz, M.S. Mansour, Combustion and Flame, 107 (1996) 223-244.

[12] R.S. Barlow, G.H. Wang, P. Anselmo-Filho, M.S. Sweeney, S. Hochgreb, Proceedings of the Combustion Institute, 32 (2009) 945-953.

[13] M.S. Sweeney, S. Hochgreb, R.S. Barlow, Combustion and Flame, 158 (2011) 935-948.

[14] M.J. Dunn, R.S. Barlow, Proceedings of the Combustion Institute, 34 (2013) 1411-1419.

[15] V. Katta, W.M. Roquemore, Proceedings of the Combustion Institute, 34 (2013) 1101-1108.

[16] A.N. Lipatnikov, J. Chomiak, Progress in Energy and Combustion Science, 31 (2005) 1-73.

[17] Y.-C. Chen, R.W. Bilger, Combustion and Flame, 138 (2004) 155-174.

[18] J.B. Bell, R.K. Cheng, M.S. Day, I.G. Shepherd, Proceedings of the Combustion Institute, 31 (2007) 1309-1317.

[19] M. Day, J. Bell, P.-T. Bremer, V. Pascucci, V. Beckner, M. Lijewski, Combustion and Flame, 156 (2009) 1035 1045.

[20] F. Liu, Ö.L. Gülder, Combustion and Flame, 143 (2005) 264-281.

[21] F. Liu, Ö.L. Gülder, Combustion Science and Technology, 180 (2008) 437-452.

[22] J.H. Chen, T. Echekki, W. Kollmann, Combustion and Flame, 116 (1999) 15-48.

[23] H.G. Im, J.H. Chen, Combustion and Flame, 131 (2002) 246-258.

[24] F. Dinkelacker, B. Manickam, S.P.R. Muppala, Combustion and Flame, 158 (2011) 1742-1749.

[25] S. Nambully, P. Domingo, V. Moureau, L. Vervisch, Combustion and Flame.

[26] S. Nambully, P. Domingo, V. Moureau, L. Vervisch, Combustion and Flame.

[27] N. Peters, Journal of Fluid Mechanics, 384 (1999) 107-132.

[28] A. Brockhinke, P. Andresen, K. Kohse-Höinghaus, Opt. Lett., 21 (1996) 2029-2031.

[29] M.S. Mansour, N. Peters, Y.-C. Chen, Symposium (International) on Combustion, 27 (1998) 767-773.

[30] Y.-C. Chen, M.S. Mansour, Symposium (International) on Combustion, 27 (1998) 811-818.

[31] R. Sankaran, E.R. Hawkes, J.H. Chen, T. Lu, C.K. Law, Proceedings of the Combustion Institute, 31 (2007) 1291 1298.

[32] A. Soika, F. Dinkelacker, A. Leipertz, Proceedings of the Combustion Institute, 27 (1998) 785-792.

[33] F. Dinkelacker, A. Soika, D. Most, D. Hofmann, A. Leipertz, W. Polifke, K. Döbbeling, Symposium (International) on Combustion, 27 (1998) 857-865.

[34] J.F. Driscoll, Progress in Energy and Combustion Science, 34 (2008) 91-134.

[35] J.M. Duclos, D. Veynante, T. Poinsot, Combustion and Flame, 95 (1993) 101-117.

[36] D. Veynante, L. Vervisch, Progress in Energy and Combustion Science, 28 (2002) 193-266.

[37] F. O'Young, R.W. Bilger, Combustion and Flame, 109 (1997) 682-700.

[38] Y.-C. Chen, R.W. Bilger, Combustion and Flame, 131 (2002) 400-435.

[39] G. Yu, C.K. Law, C.K. Wu, Combustion and Flame, 63 (1986) 339-347.

[40] F. Fuest, R.S. Barlow, D. Geyer, F. Seffrin, A. Dreizler, Proceedings of the Combustion Institute, 33 (2011) 815822.

[41] D. Geyer, 1D-Raman/Rayleigh Experiments in a Turbulent Opposed-Jet, Technical University of Darmstadt, Germany, 2005.

[42] J.J. Driscoll, V. Sick, P.E. Schrader, R.L. Farrow, Proceedings of the Combustion Institute, 29 (2002) 2719-2726.

[43] J. Frank, S. Kaiser, Exp Fluids, 49 (2010) 823-837. 
[44] P. Holoborodko, Smooth Noise Robust Differentiators, http://www.holoborodko.com/pavel/numericalmethods/numerical-derivative/smooth-low-noise-differentiators/, 2013

[45] A.N. Karpetis, T.B. Settersten, R.W. Schefer, R.S. Barlow, Opt. Lett., 29 (2004) 355-357.

\section{Figure Captions}

Fig. 1. Annular bluff-body burner (left). Bluff-body stabilized flame for $\Phi=1.23$ and $U_{b} / S_{L}=26$ (center), and 5.5 (right).

Fig. 2. Concentration (left) and temperature (right) measurements in a set of premixed $\mathrm{CH}_{4}$-air flat flames. Symbols are measurements, lines are calculations. Error-bars are $\pm \sigma$.

Fig. 3. Mean flame thickness (blue curve) as function of the measured flame-front angle. Error bars are $\pm \sigma$. The red curve indicates the fraction of measurements with measured flame-front angle lower than $\theta$. Vertical dotted line is the threshold above which measurements are rejected.

Fig. 4. Measured results for mean species mass fraction and selected atom ratios in the vertical flame (blue curve), plotted versus the displacement normal to the flame, and compared with an unstrained laminar flame calculation at $\Phi=0.7$ (red dotted line). Black dots are single-shot measurements.

Fig. 5. 3D progress variable gradient (left) and scalar dissipation (right) for the vertical flame, plotted against the progress variable and compared to laminar flame calculation at $\Phi=0.7$ (red dotted line). Black dots are single-shot measurements.

Fig. 6 Measured conditional mean scalars in the bluff-body flame series with $\Phi=0.75,10 \mathrm{~mm}$ from the bluff-body, for 3 ratios of reactant bulk velocity to the laminar flame speed. Chemkin laminar unstrained flame results (dashed black line) and opposed flow calculations (dashed red line) for a strain rate of $3500 \mathrm{~s}^{-1}$ are included. Arrows indicate the trend with increasing bulk velocity.

Fig. 7 Measured conditional mean scalars in the bluff-body flame series with $\Phi=0.75$, for $U_{b} / S_{L}=52$, for distances from the bluff-body ranging from $5 \mathrm{~mm}$ to $20 \mathrm{~mm}$. Chemkin laminar unstrained flame results (dashed black line) and opposed flow calculations (dashed red line) for a strain rate of $3500 \mathrm{~s}^{-1}$ are included. Arrows indicate the trend with increasing axial distance.

Fig. 8. Measured angle between the flame-front and axial direction, as funtion of the distance from the burner.

Fig. 9. Schematic diagram of the recirculation zone (RZ) and the flame-brush for a low-speed (left) and a high-speed (right) case.

Fig. 10. Average profiles of $\mathrm{C} / \mathrm{H}$ atom ratio (top row), $\mathrm{CO}_{2}$ and $\mathrm{H}_{2} \mathrm{O}$ mass fractions (middle 2 rows), and temperature (last row) versus the radial distance, at $\Phi=0.75$ for 3 ratios of bulk reactants velocity to laminar flame speed (left column $U_{b} / S_{L}=5.2$, center $U_{b} / S_{L}=31$, right $U_{b} / S_{L}=52$ ). Data are plotted for distances from the bluff-body ranging from 5 to $20 \mathrm{~mm}$.

Fig. 11 The plots in the top row show temperature and $\mathrm{H}_{2} \mathrm{O}$ mass fraction for the $U_{b} / S_{L}=5.2, \Phi=0.75, \mathrm{z}=10 \mathrm{~mm}$ versus the radial coordinate. The red curve is the average profile, the blue curves are single-shot profiles, and the dotted-black profile is from unstrained Chemkin calculation. The center row shows the same profiles of the top row, projected along the direction normal to the flame-front. The bottom row shows profiles for the $U_{b} / S_{L}=52$ case, projected onto the normal to the flame-front. The dashed cyan lines are profiles from opposed flow laminar calculations with a strain rate of $3500 \mathrm{~s}^{-1}$.

Fig. 12. Profiles of 3D progress variable gradient and 3D scalar dissipation versus progress variable for $\Phi=0.75$, with 3 ratios of bulk reactant velocities to laminar flame speed (left column $U_{b} / S_{L}=5.2$, center $U_{b} / S_{L}=31$, right $U_{b} / S_{L}=52$ ), at distances from the bluff-body of 10,12.5 and $15 \mathrm{~mm}$. Scatter data are shown for $z=10 \mathrm{~mm}$

Fig. 13. Measured conditional mean scalars in the bluff-body flame series with $\Phi=1.23,10 \mathrm{~mm}$ from the bluff-body, for 3 ratios of reactant bulk velocity to the laminar flame speed. Chemkin laminar unstrained flame results (dashed black line) and opposed flow calculations (dashed red line) for a strain rate of $3500 \mathrm{~s}^{-1}$ are included. Arrows indicate the trend with increasing bulk velocity.

Fig. 14 Measured conditional mean scalars in the bluff-body flame series with $\Phi=1.23$, for $U_{b} / S_{L}=26$, for distances from the bluff-body ranging from $5 \mathrm{~mm}$ to $20 \mathrm{~mm}$. Chemkin laminar unstrained flame results (dashed black line) and opposed flow 
calculations (dashed red line) for a strain rate of $3500 \mathrm{~s}^{-1}$ are included. Arrows indicate the trend with increasing axial distance.

Fig. 15 Average profiles of $\mathrm{C} / \mathrm{H}$ atom ratio (top row), $\mathrm{CO}_{2}$ and $\mathrm{H}_{2} \mathrm{O}$ mass fractions (middle 2 rows), and temperature (last row) versus the radial distance, at $\Phi=1.23$ for 3 ratios of bulk reactants velocity to laminar flame speed (left column $U_{b} / S_{L}=5.5$, center $U_{b} / S_{L}=9.3$, right $U_{b} / S_{L}=26$ ). Data are plotted for distances from the bluff-body ranging from 5 to $20 \mathrm{~mm}$.

Fig. 16 The plots in the top row show temperature and $\mathrm{H}_{2} \mathrm{O}$ mass fraction profiles projected onto the direction normal to mean flame-front for $\Phi=1.23$, taken $10 \mathrm{~mm}$ from the surface of the bluff-body, for three ratios of $U_{b} / S_{L}$. The blue curves are singleshot profiles for the $U_{b} / S_{L}=26$ case, the dotted-black and red profiles are from unstrained and strained Chemkin calculations. The bottom row shows the same profiles of the top row, obtained for $U_{b} / S_{L}=26$ at distance from the bluff-body burner ranging from 10 to $20 \mathrm{~mm}$.

Fig. 17 Profiles of 3D progress variable gradient and 3D scalar dissipation versus progress variable for $\Phi=1.23$, with three ratios of bulk reactant velocities to laminar flame speed (left column $U_{b} / S_{L}=5.5$, center $U_{b} / S_{L}=9.3$, right $U_{b} / S_{L}=26$ ), at distances from the bluff-body of 10, 12.5, 15 and $20 \mathrm{~mm}$. Scatter data are shown for $z=10 \mathrm{~mm}$ 
Table 1: Bulk velocity $U_{b}$, ratio of reactant bulk velocity to laminar speed $U_{b} / S_{L}$, and Reynolds number based on the hydraulic diameter $\boldsymbol{R e}_{D h}$ for the test cases examined. Hydraulic diameter $D_{h}=12.6 \mathrm{~mm}$ is the difference between outer and inner diameter of the annulus.

\begin{tabular}{cccccc}
\hline \multicolumn{3}{c}{$\Phi=0.75$} & \multicolumn{3}{c}{$\Phi=1.23$} \\
\hline$U_{b}(\mathrm{~m} / \mathrm{s})$ & $U_{b} / S_{L}$ & $R e_{D h}$ & $U_{b}(\mathrm{~m} / \mathrm{s})$ & $U_{b} / S_{L}$ & $R e_{D h}$ \\
1.3 & 5.2 & 1060 & 2 & 5.5 & 1660 \\
7.7 & 31 & 6350 & 3.4 & 9.3 & 2770 \\
12.9 & 52 & 10580 & 9.5 & 26 & 7750 \\
\hline
\end{tabular}


Table 1: Representative values for precision and repeatability in scalar measurements. Precision and repeatability are expressed as percentage of the mean value. Mean values for species are mass fractions.

\begin{tabular}{ccccc}
\hline Scalar & $\begin{array}{c}\text { Precision } \\
\boldsymbol{\sigma ( \% )}\end{array}$ & $\begin{array}{c}\text { Repeatability } \\
(\%)\end{array}$ & $\begin{array}{c}\text { Premixed } \\
\text { Flame }\end{array}$ & $\begin{array}{c}\text { Mean } \\
\text { Value }\end{array}$ \\
\hline$T(K)$ & 0.7 & 0.9 & $\Phi=1.01$ & 2186 \\
$\mathrm{~N}_{2}$ & 0.7 & 0.3 & $\Phi=1.01$ & 0.715 \\
$\mathrm{CO}_{2}$ & 3.2 & 1.5 & $\Phi=1.01$ & 0.134 \\
$\mathrm{H}_{2} \mathrm{O}$ & 2.0 & 0.9 & $\Phi=1.01$ & 0.122 \\
$\mathrm{CO}$ & 5.3 & 1.1 & $\Phi=1.29$ & 0.066 \\
$\mathrm{H}_{2}$ & 7.0 & 1.1 & $\Phi=1.29$ & 0.003 \\
$\Phi$ & 1.6 & 0.4 & $\Phi=1.01$ & 1.02 \\
$\mathrm{C} / \mathrm{H}$ & 3.8 & 0.58 & $\Phi=1.29$ & 0.25 \\
$\mathrm{C} / \mathrm{O}$ & 3.1 & 0.8 & $\Phi=1.29$ & 0.33 \\
$\mathrm{O}_{2}$ & 1.0 & 1.8 & Air & 0.23 \\
\hline
\end{tabular}


Figure 1

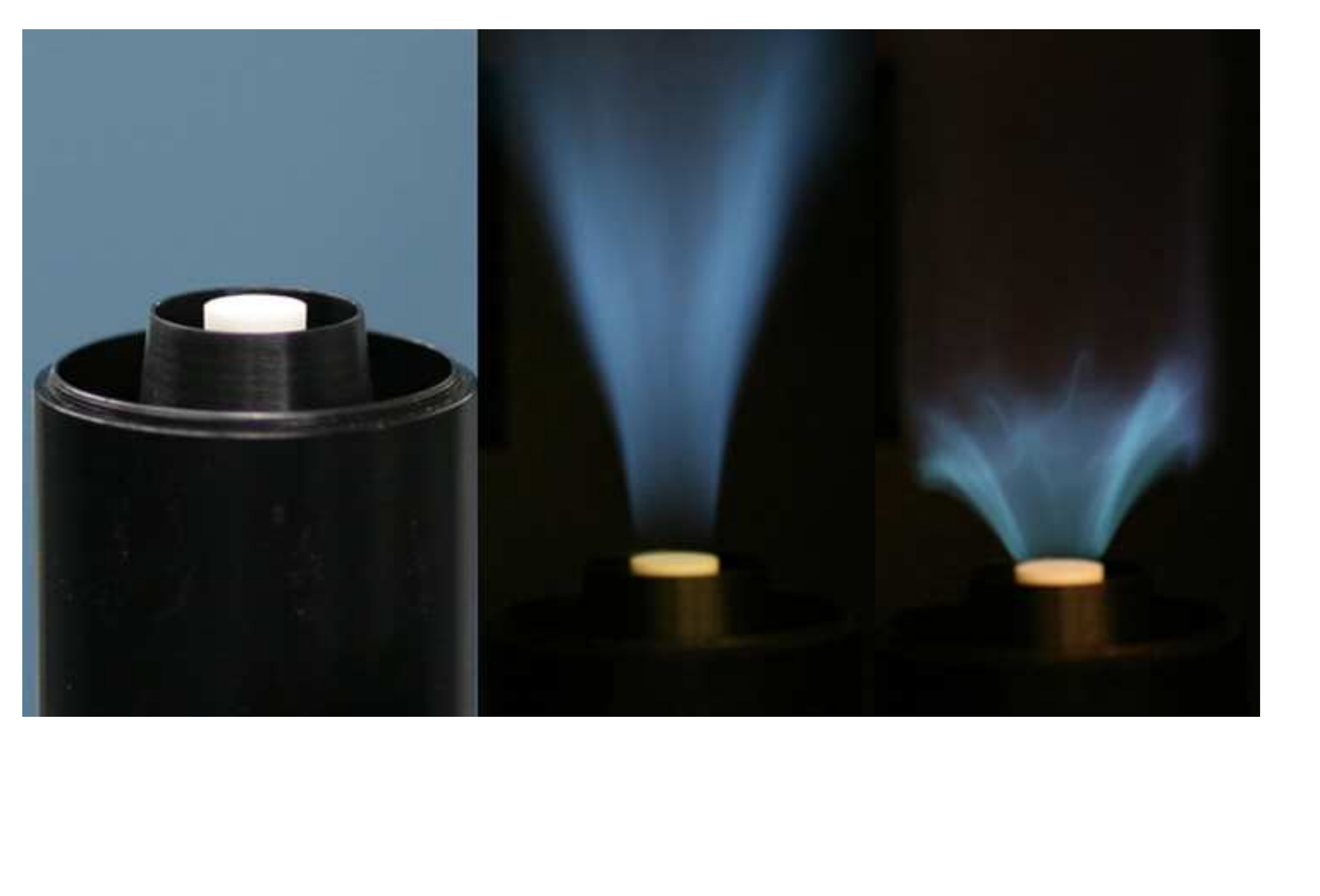

Figure 1

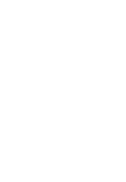

.
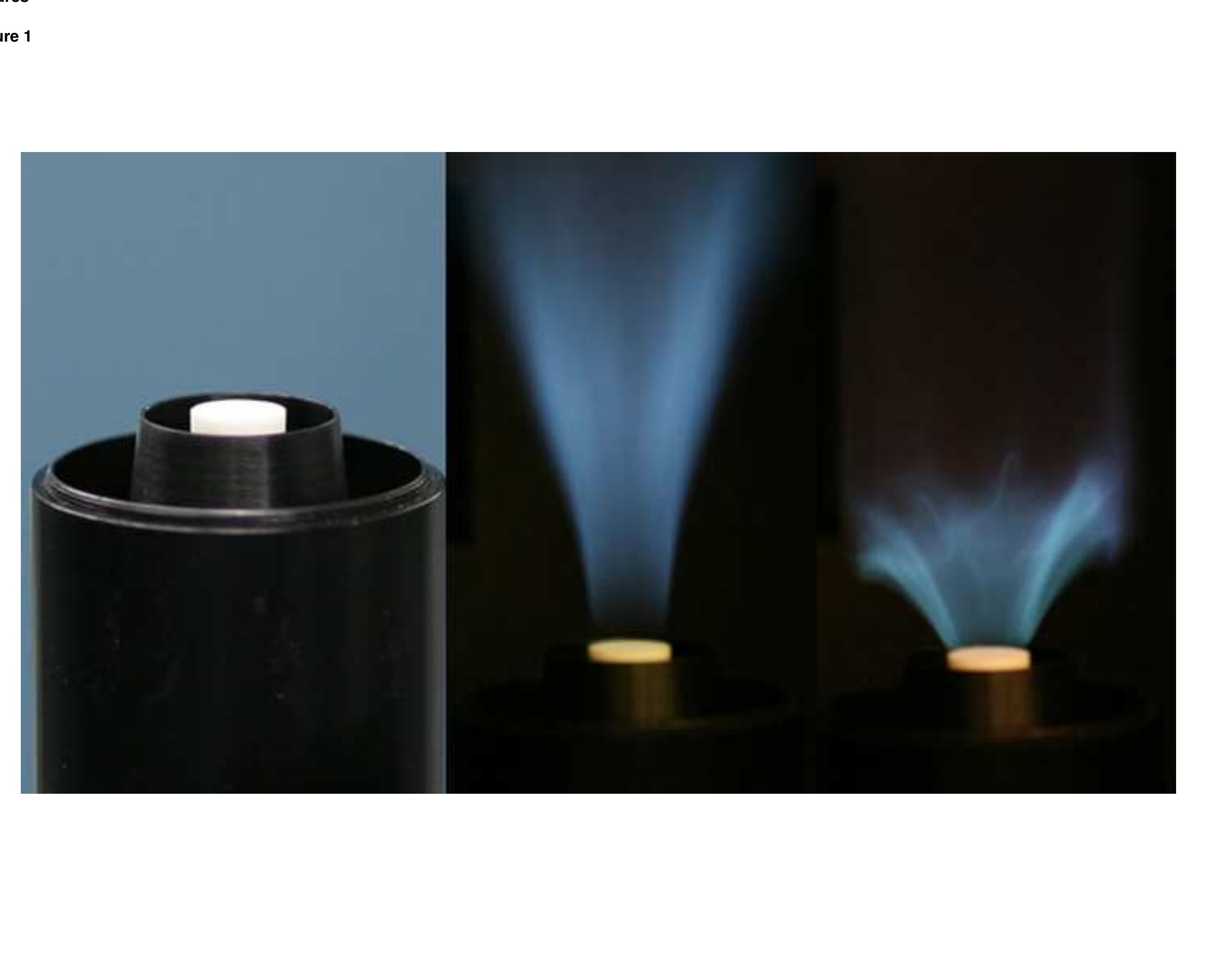

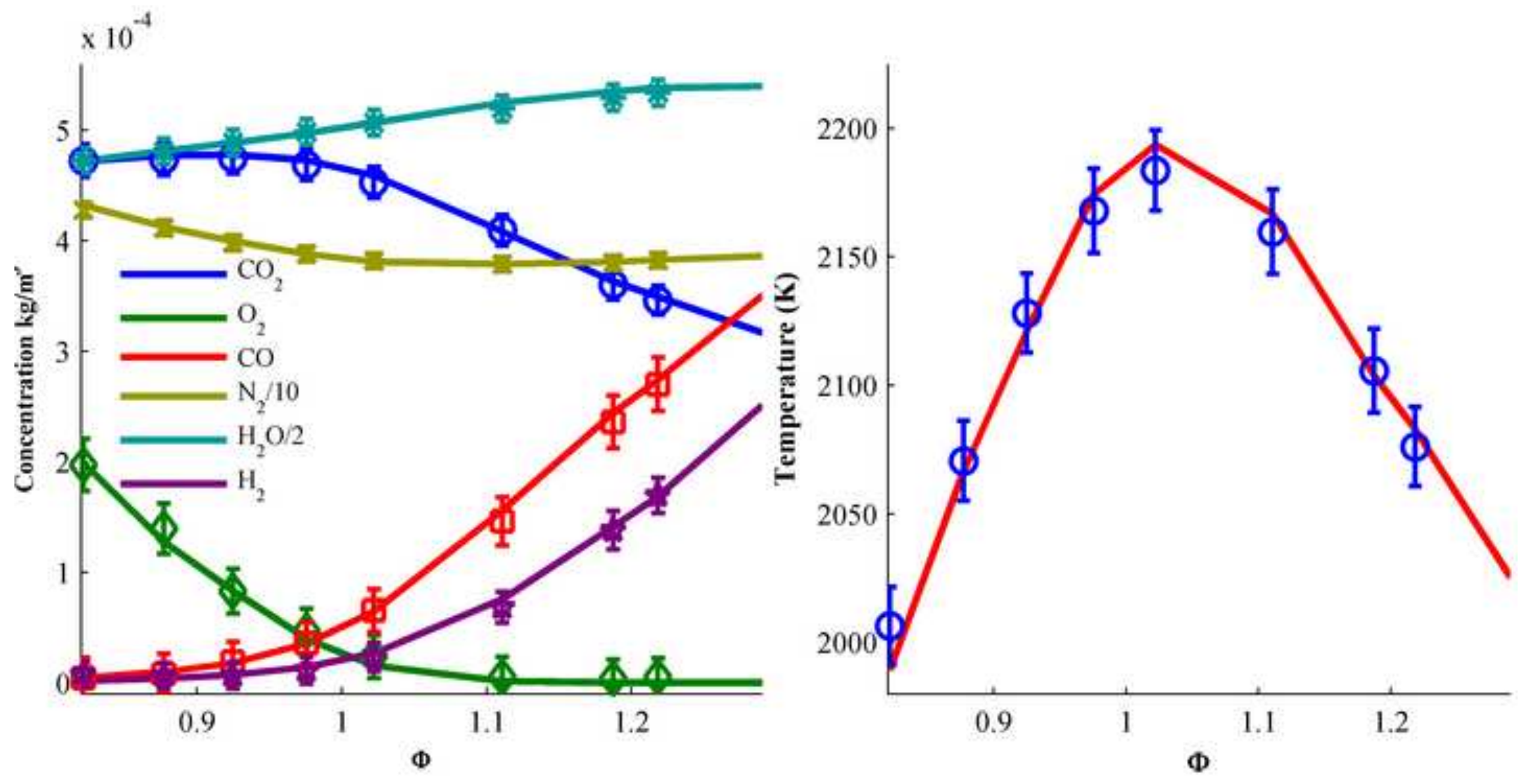


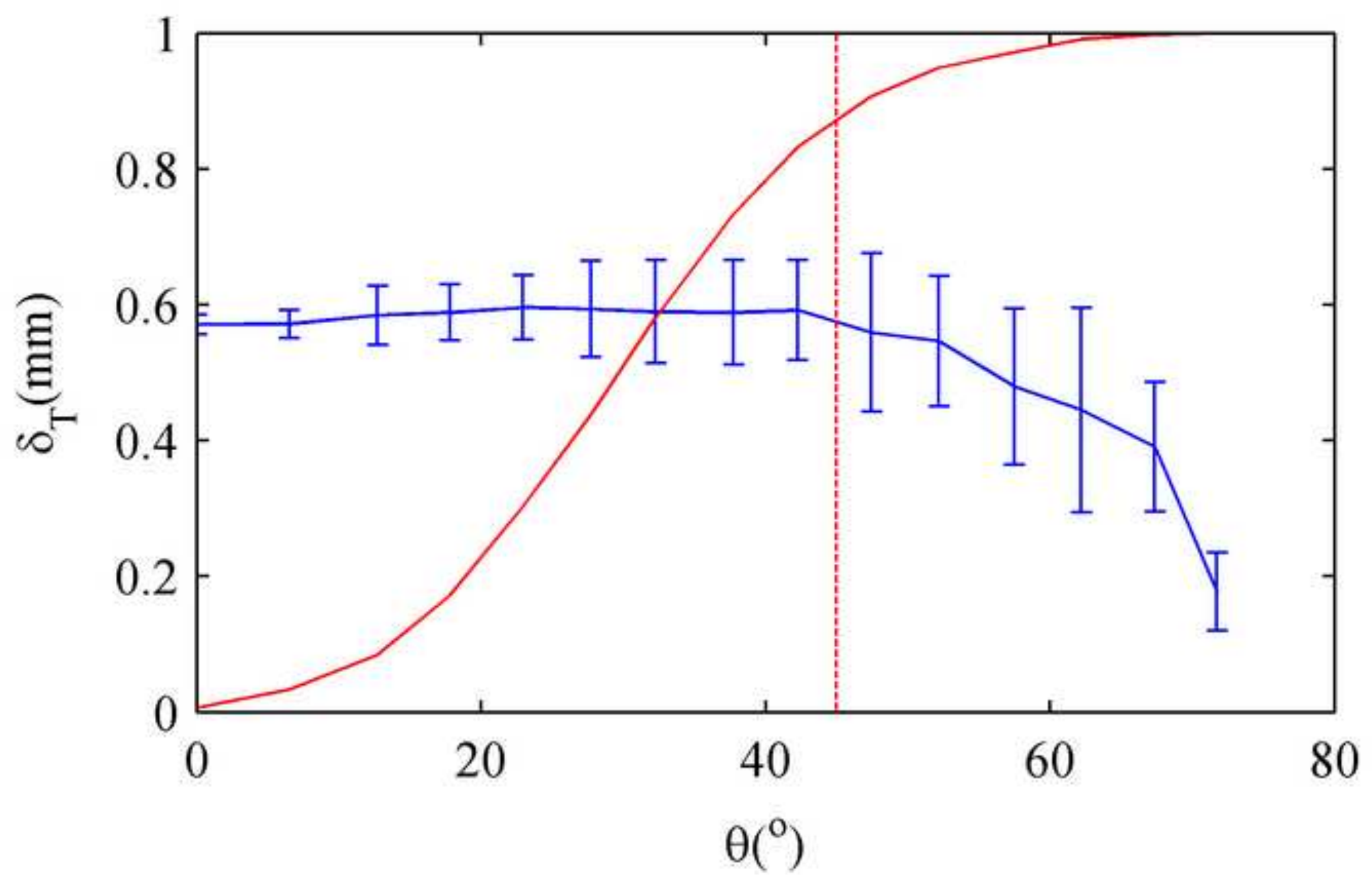



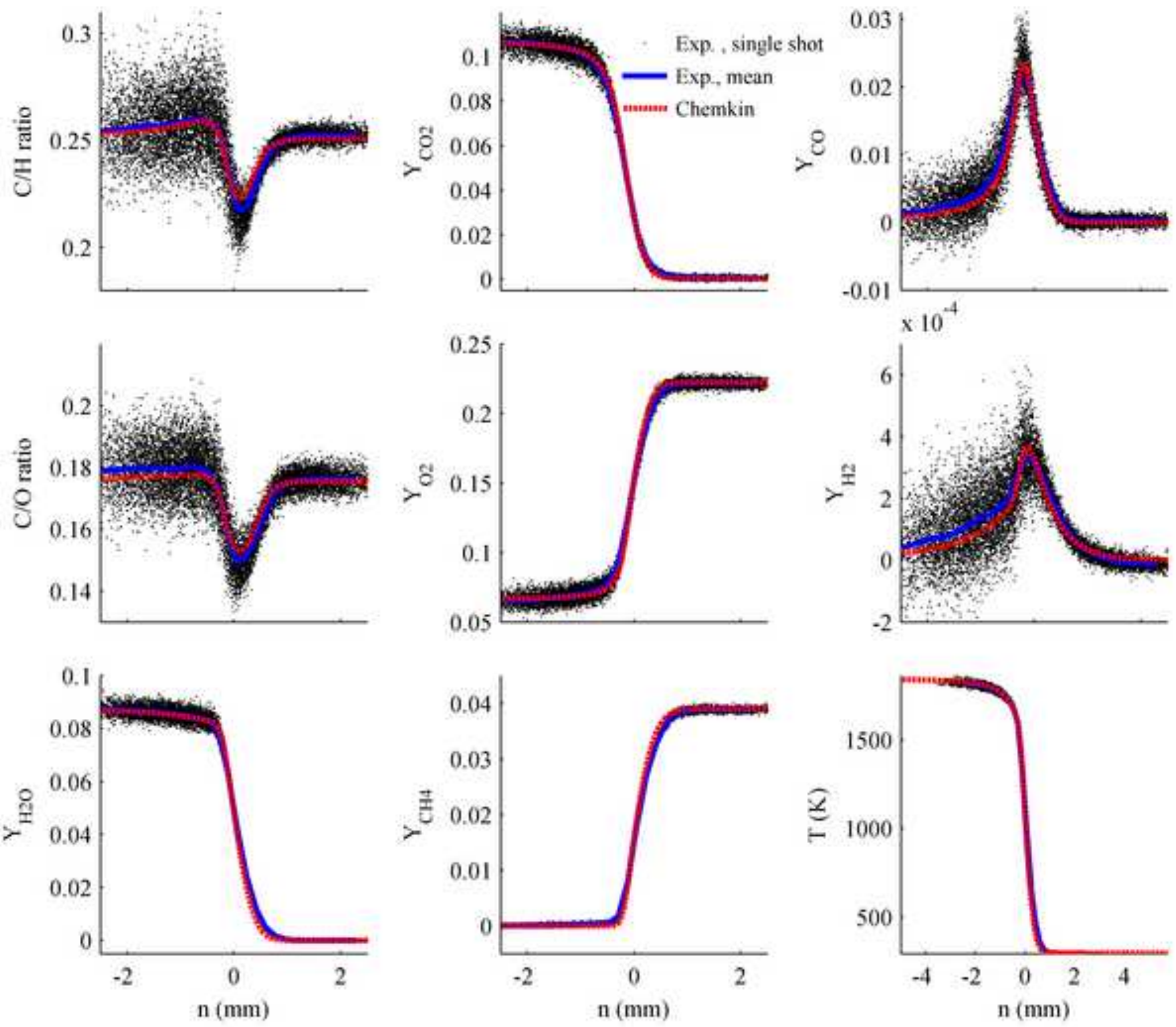

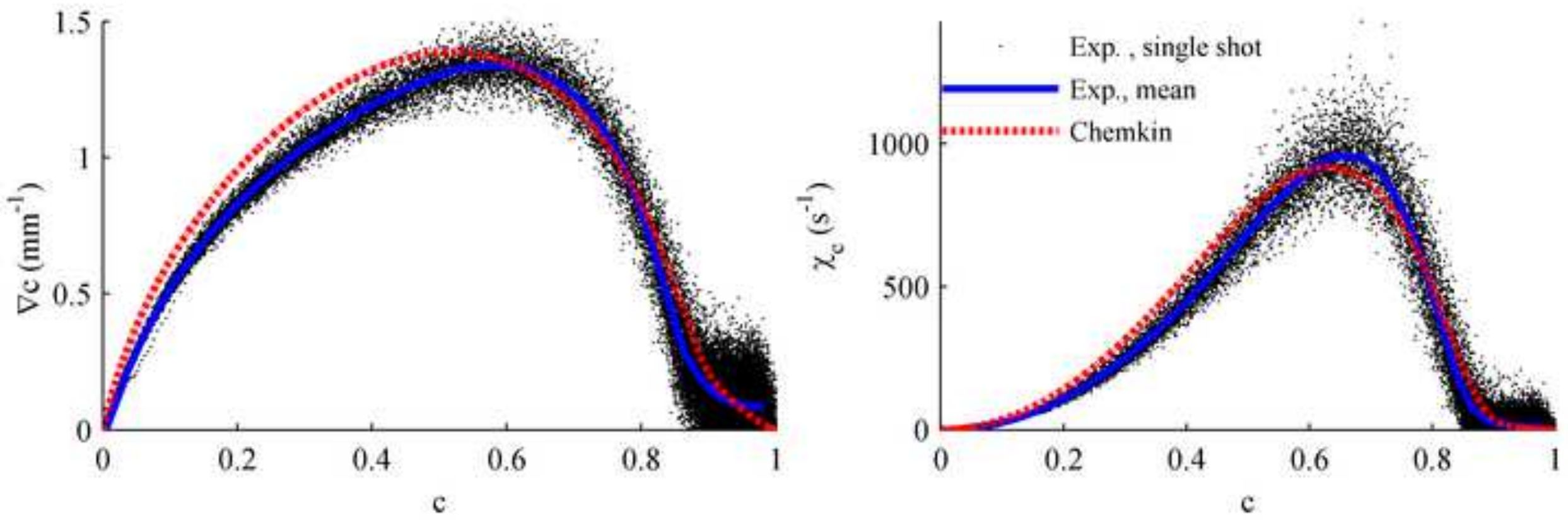

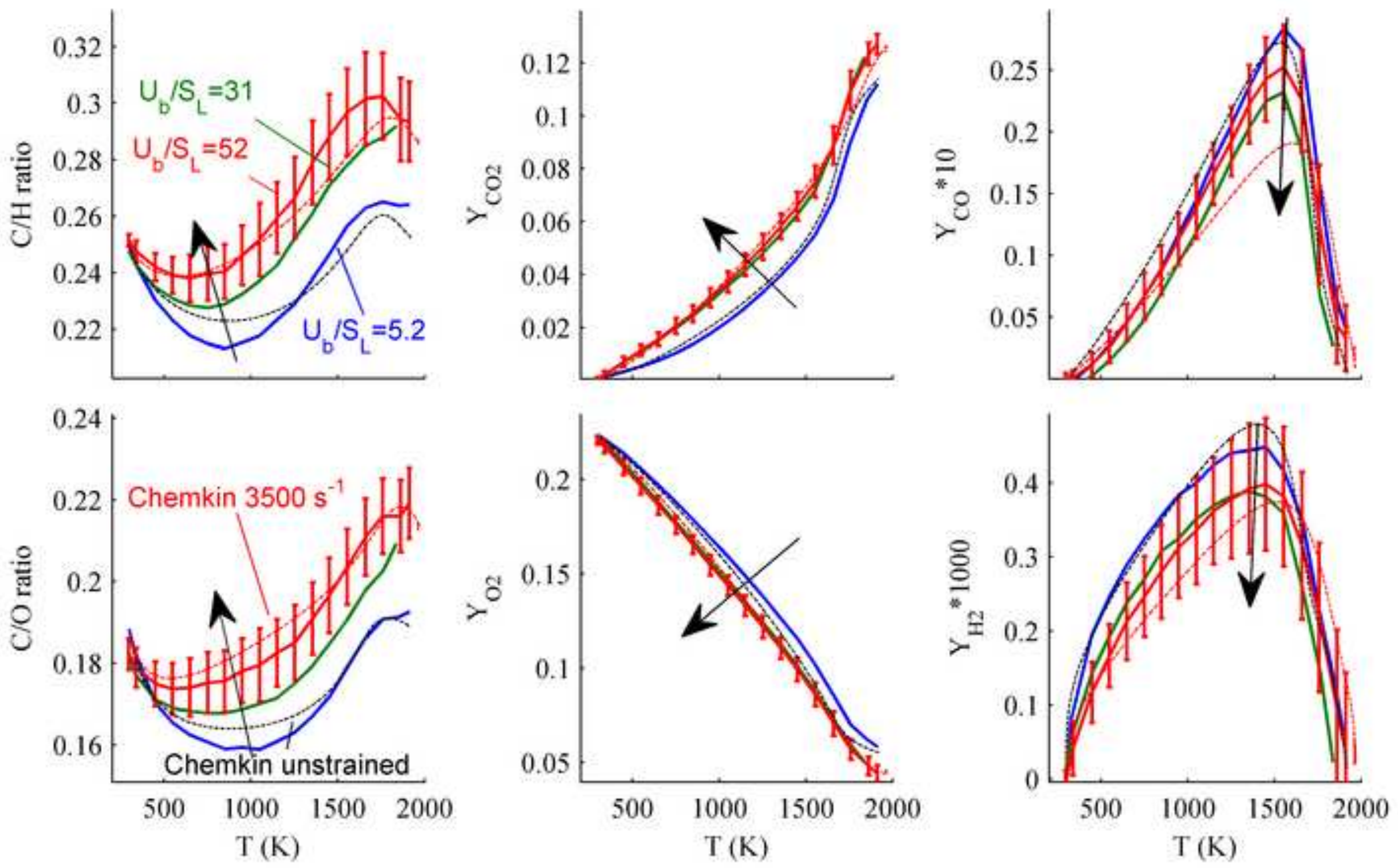

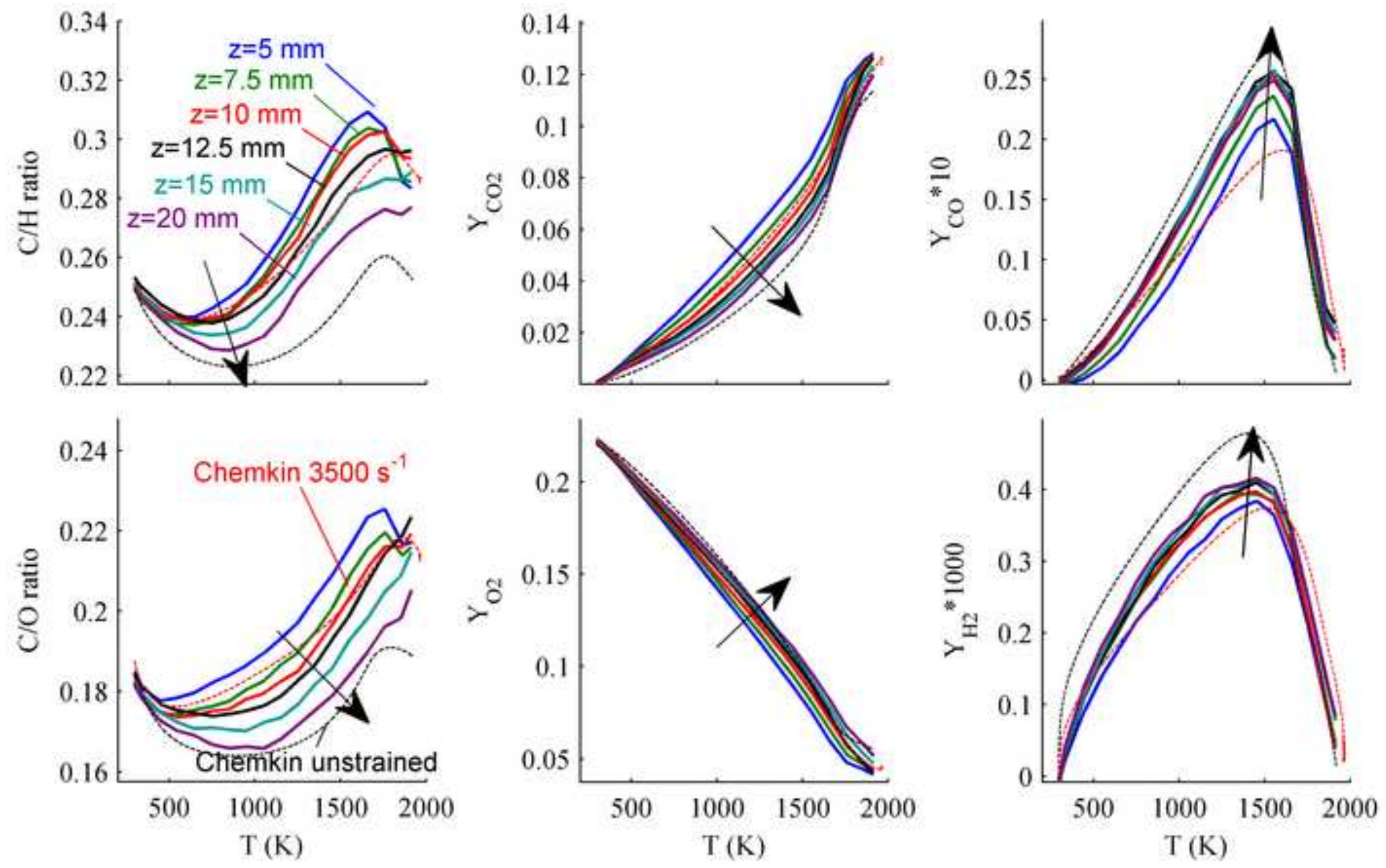


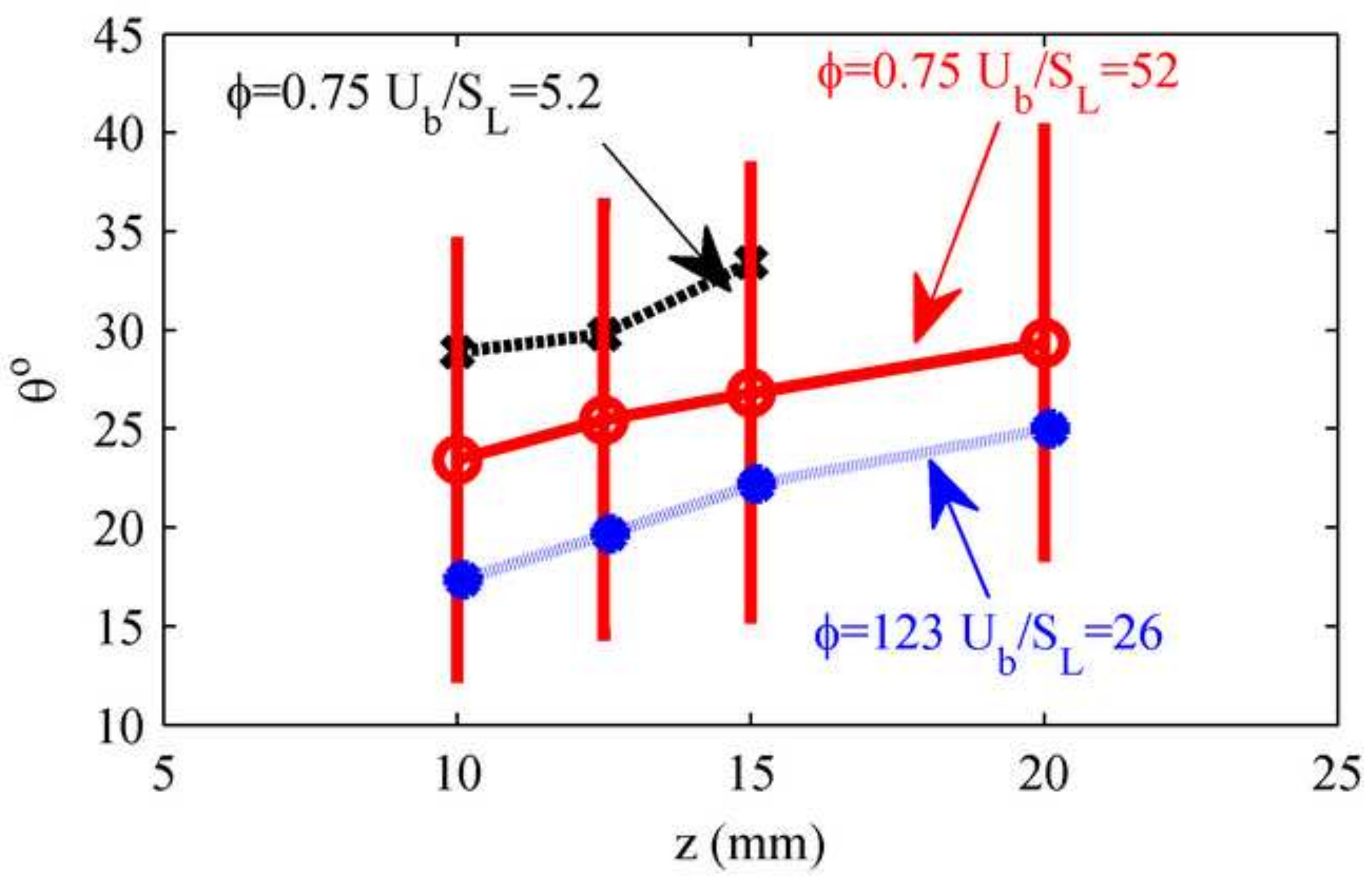




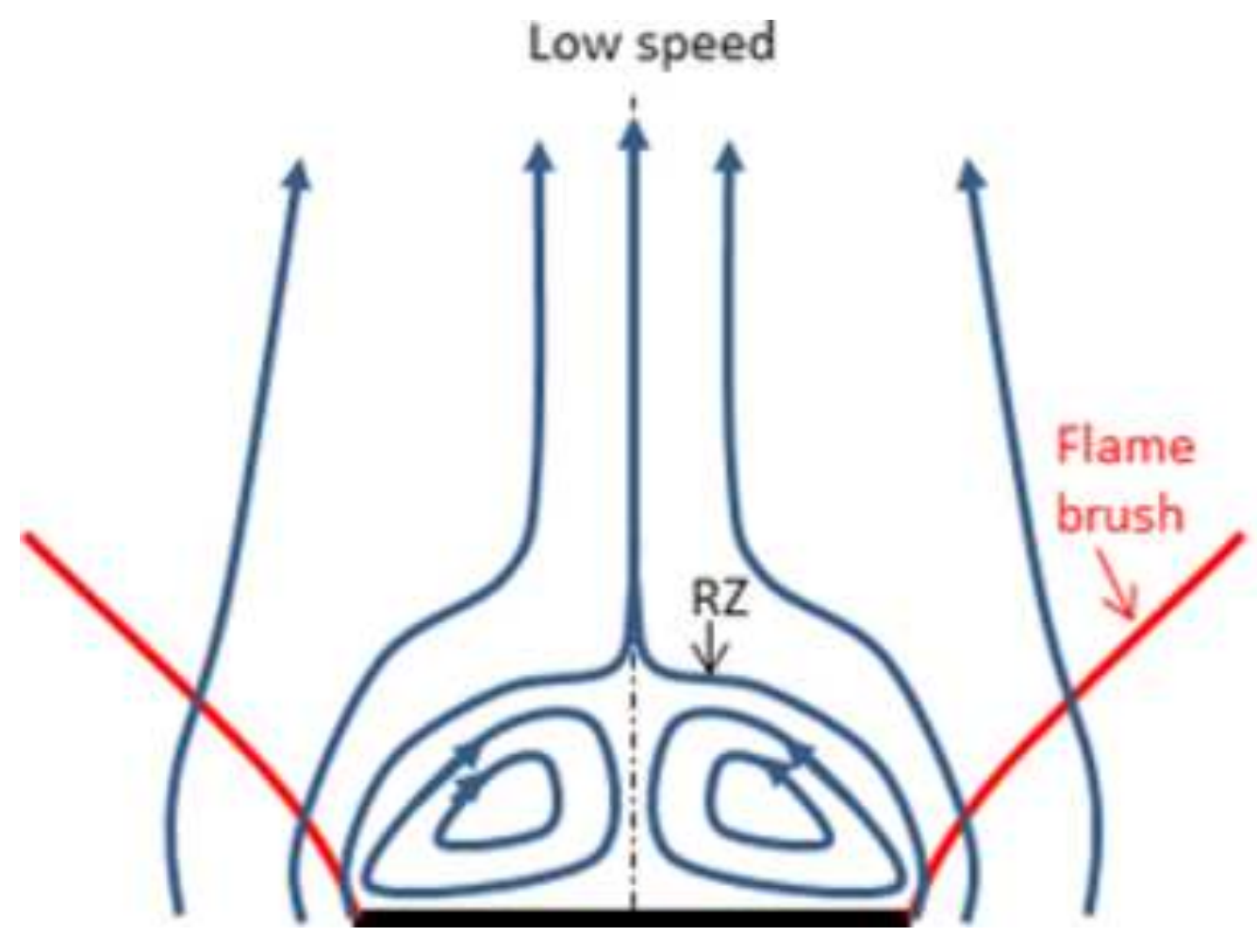

High speed

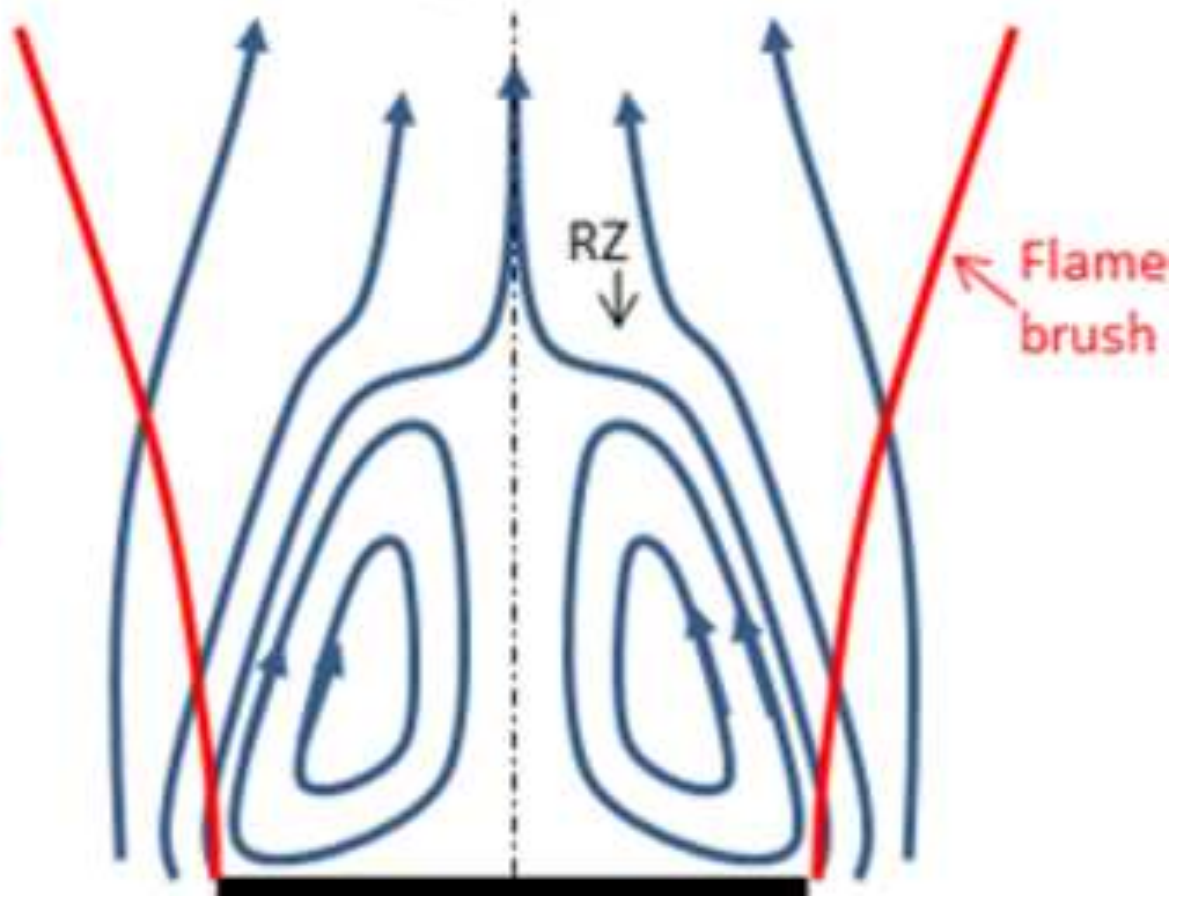




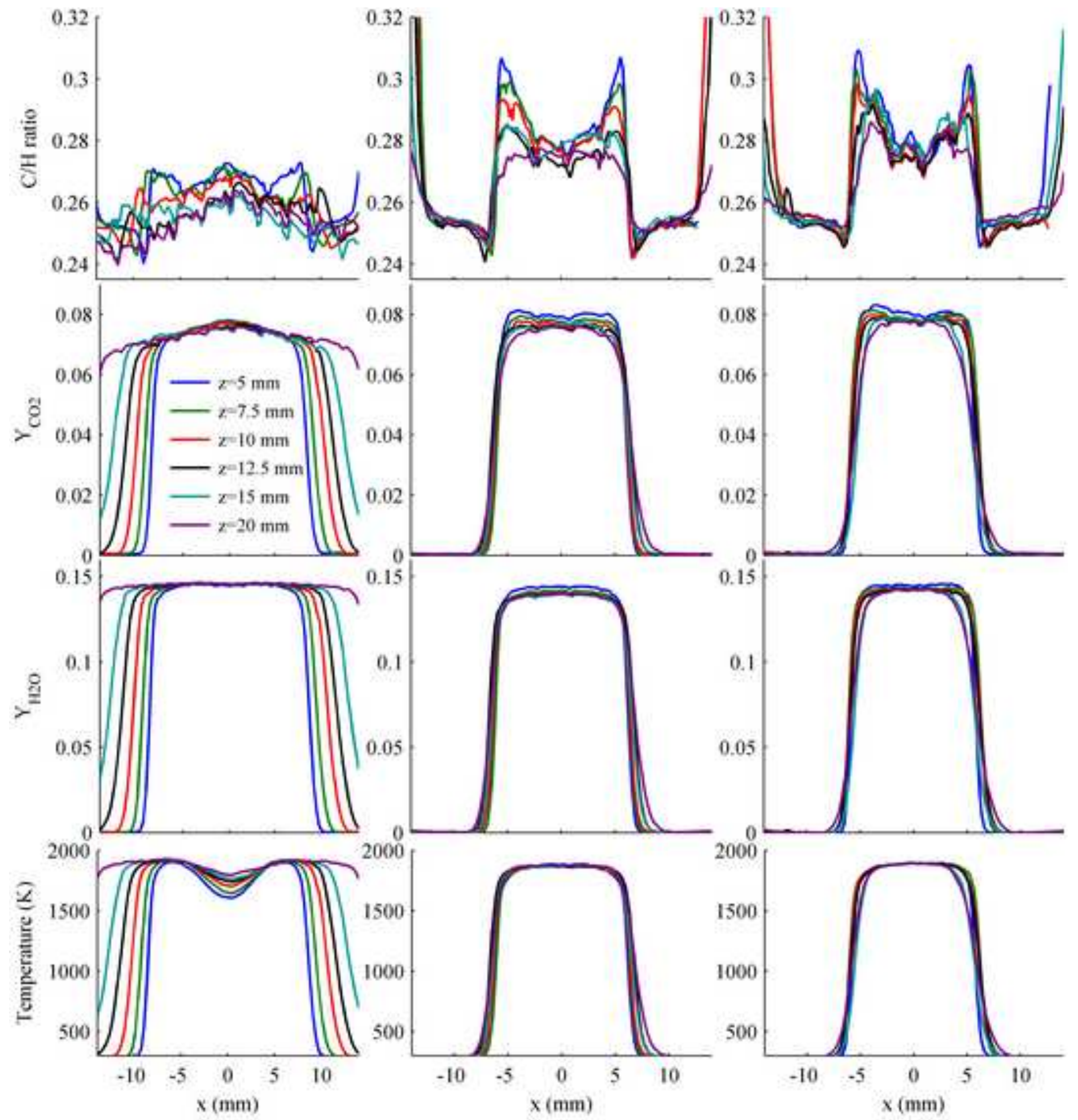



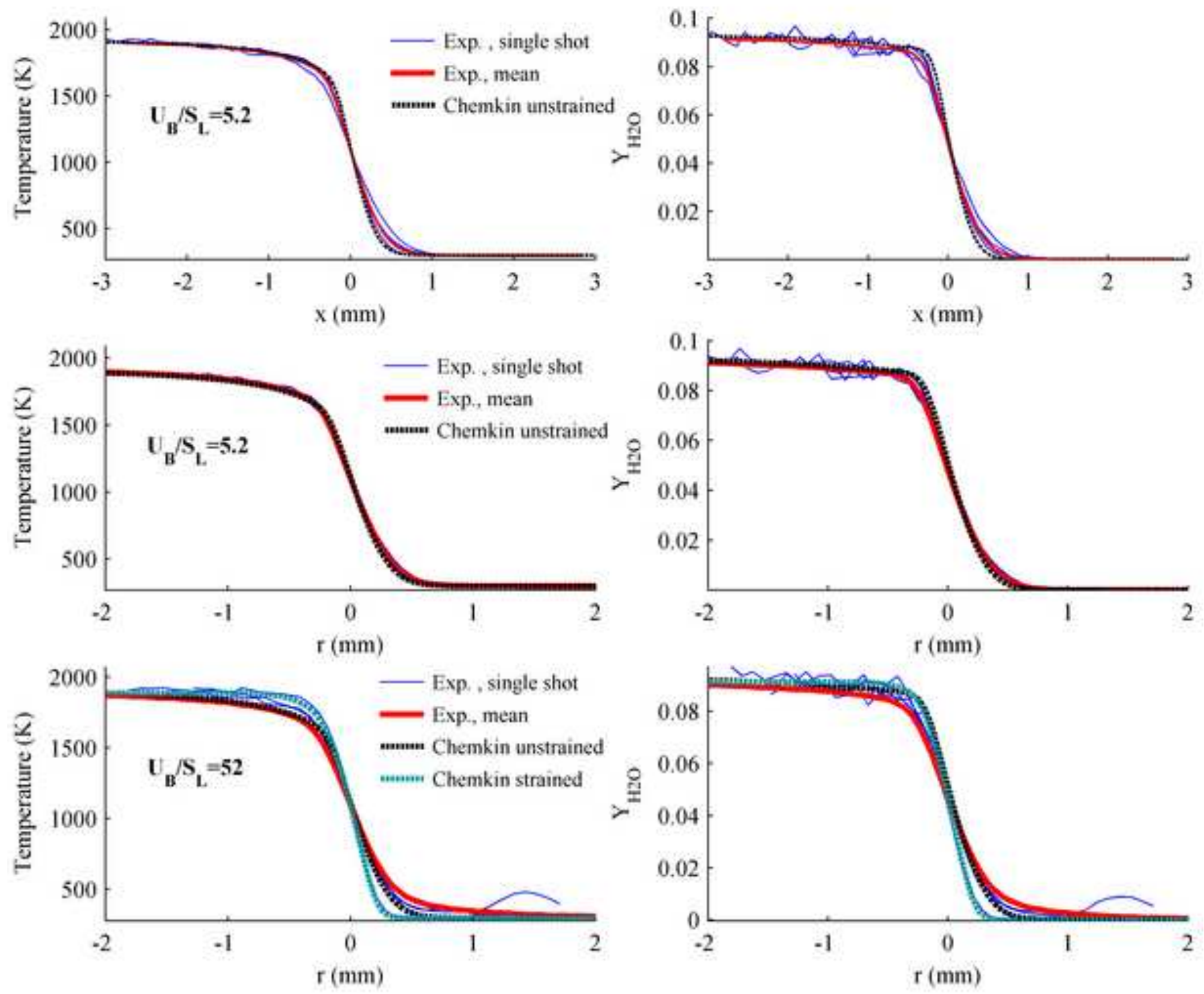


$$
\hat{A} \cap
$$



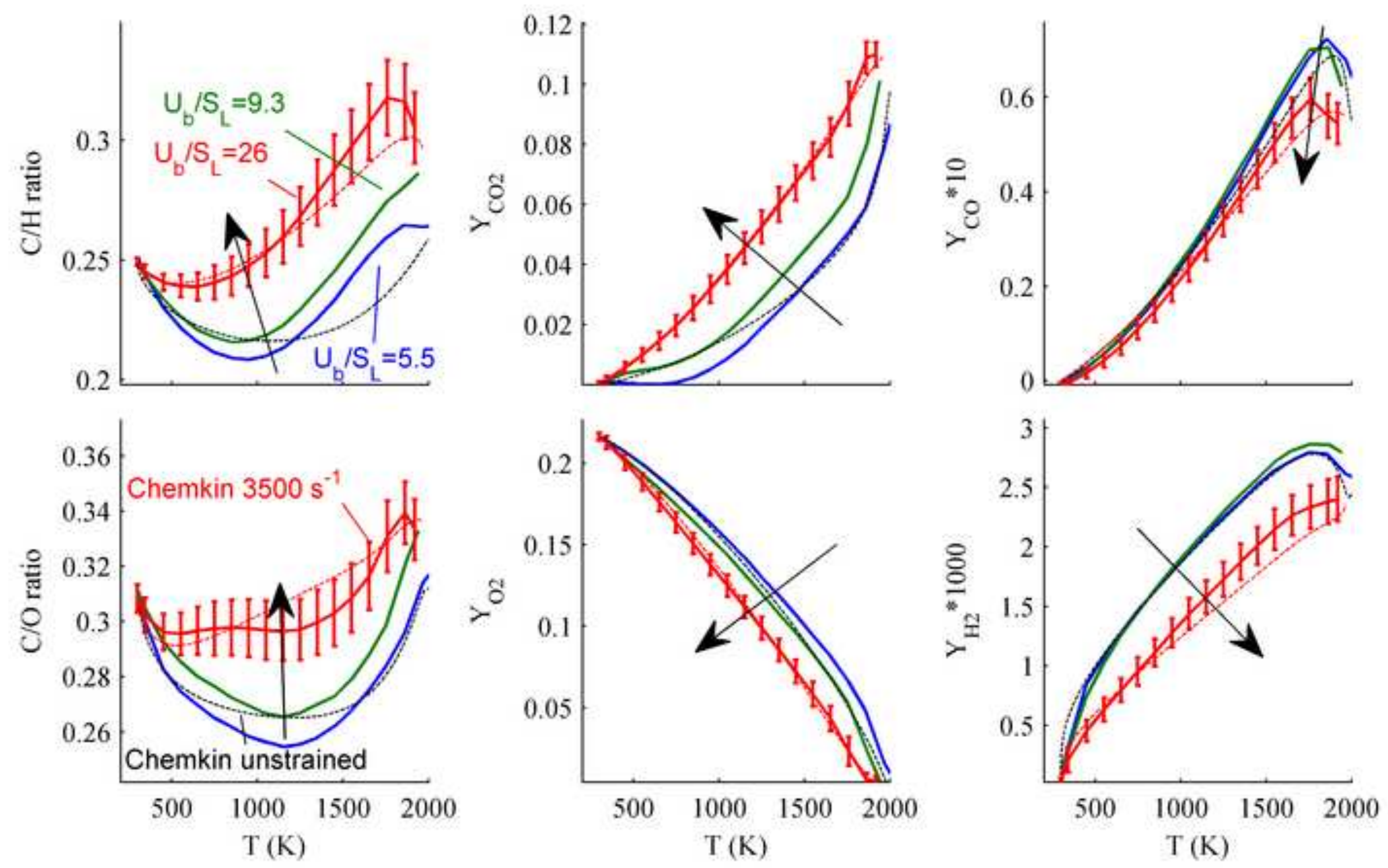

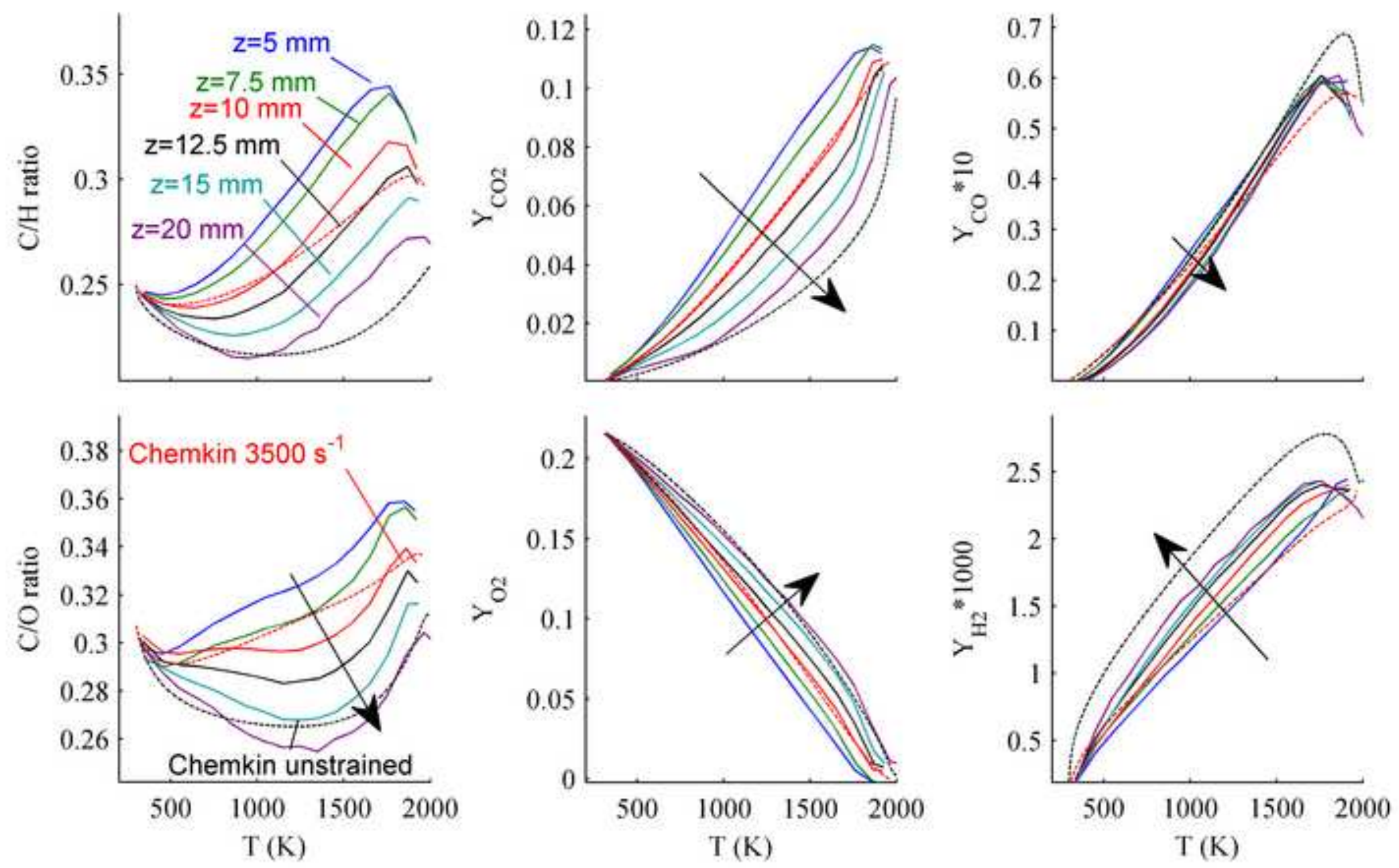


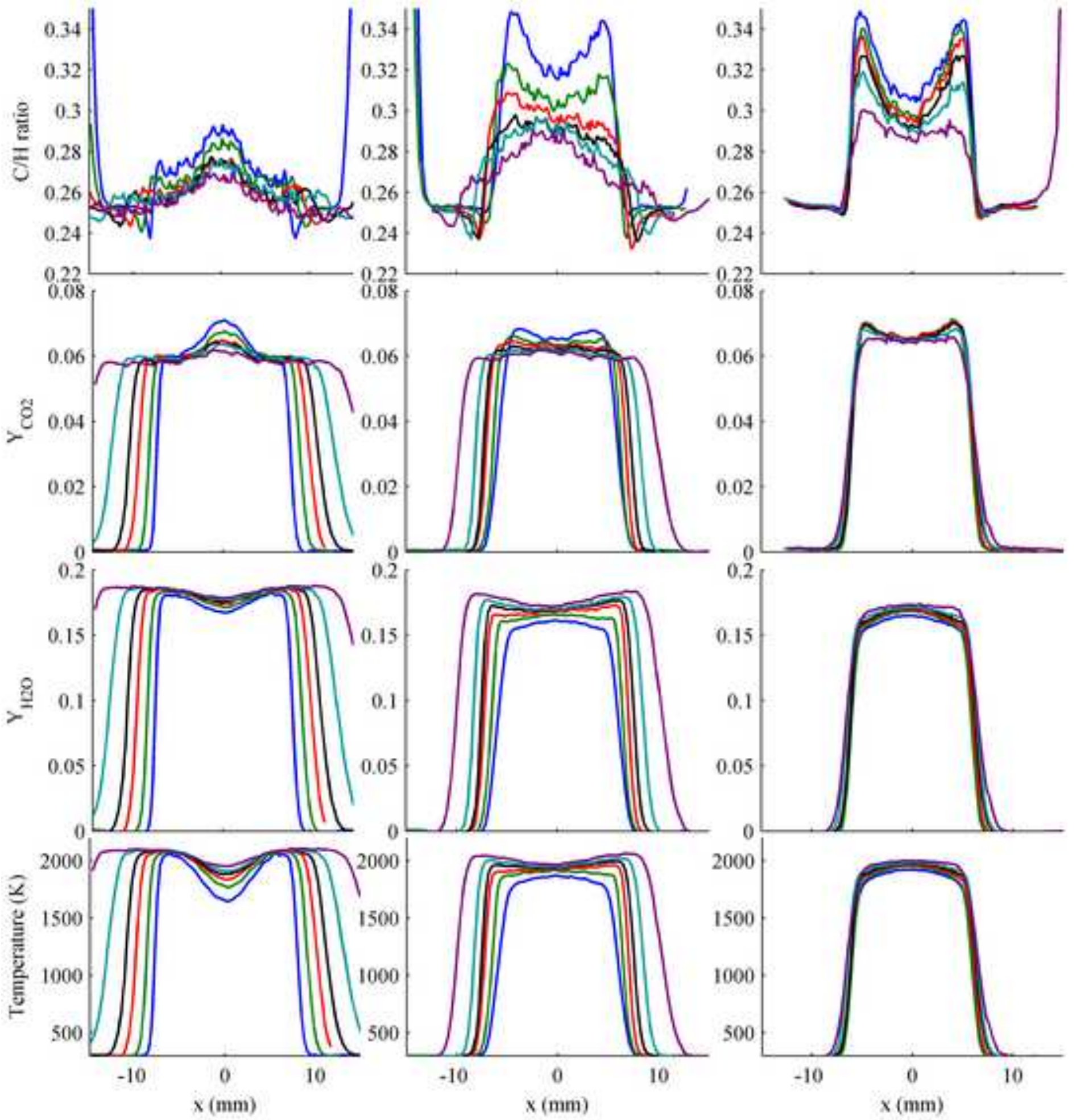



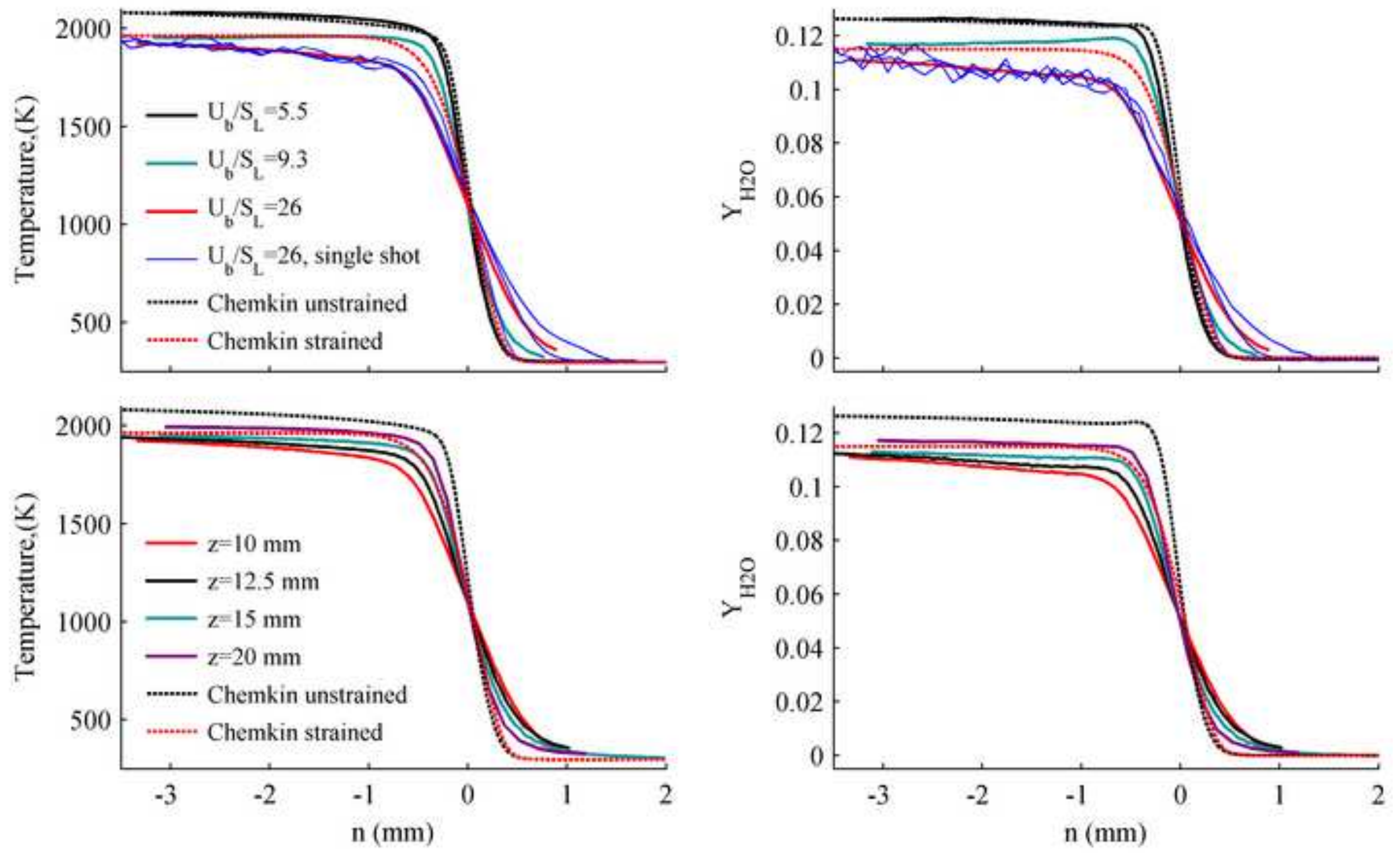

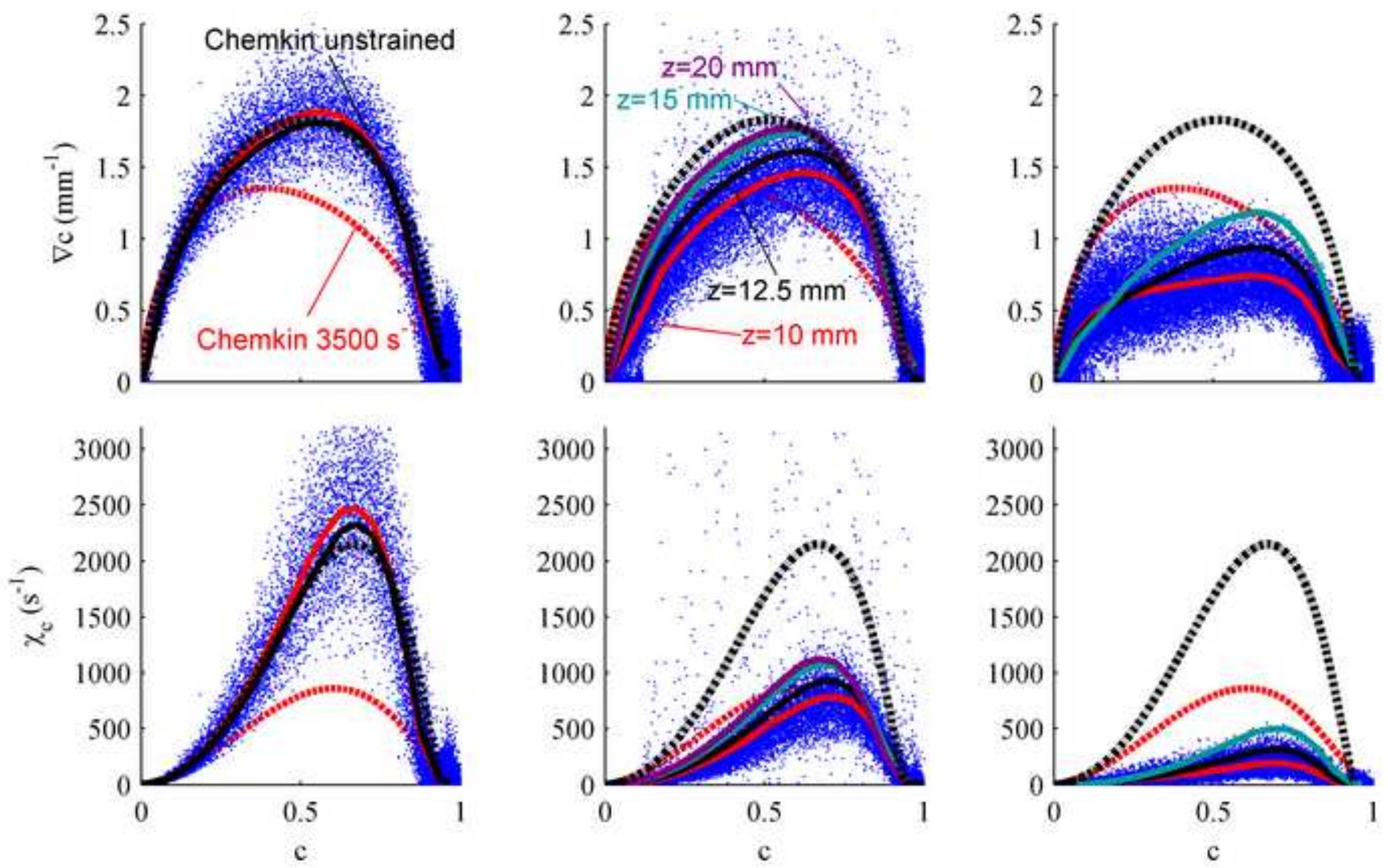